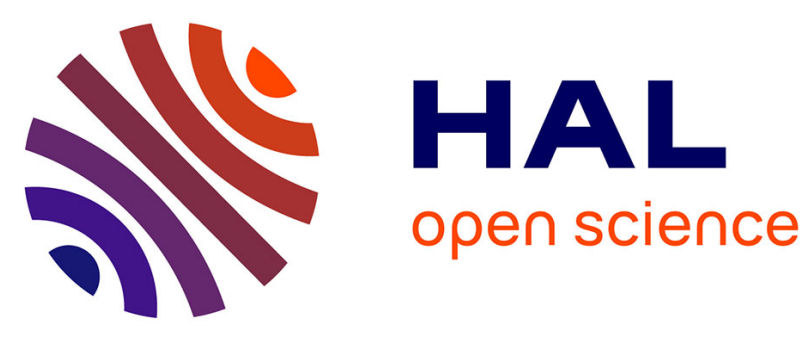

\title{
Enantioselective Organocatalyzed Domino Synthesis of Six-Membered Carbocycles
}

\author{
Sébastien Goudedranche, Wilfried Raimondi, Xavier Bugaut, Thierry \\ Constantieux, Damien Bonne, Jean Rodriguez
}

\section{To cite this version:}

Sébastien Goudedranche, Wilfried Raimondi, Xavier Bugaut, Thierry Constantieux, Damien Bonne, et al.. Enantioselective Organocatalyzed Domino Synthesis of Six-Membered Carbocycles. Synthesis: Journal of Synthetic Organic Chemistry, 2013, 45, pp.1909-1930. 10.1055/s-0033-1338484 . hal00861699

\section{HAL Id: hal-00861699 \\ https://hal.science/hal-00861699}

Submitted on 16 Sep 2013

HAL is a multi-disciplinary open access archive for the deposit and dissemination of scientific research documents, whether they are published or not. The documents may come from teaching and research institutions in France or abroad, or from public or private research centers.
L'archive ouverte pluridisciplinaire HAL, est destinée au dépôt et à la diffusion de documents scientifiques de niveau recherche, publiés ou non, émanant des établissements d'enseignement et de recherche français ou étrangers, des laboratoires publics ou privés. 


\title{
Enantioselective Organocatalyzed Domino Synthesis of Six-Membered Carbocycles
}

\author{
Sébastien Goudedranche, ${ }^{\mathrm{a}}$ Wilfried Raimondi, ${ }^{\mathrm{a}}$ Xavier Bugaut, ${ }^{\mathrm{a}}$ Thierry Constantieux, ${ }^{\mathrm{a}}$ Damien Bonne ${ }^{* \mathrm{a}}$ and Jean \\ Rodriguez, ${ }^{\text {a }}$ \\ ${ }^{a}$ Aix Marseille Université, CNRS, iSm2 UMR 7313, 13397 Marseille, France. \\ Fax: +33491289187 \\ E-mail: jean.rodriguez@univ-amu.fr or damien.bonne@univ-amu.fr \\ Received: The date will be inserted once the manuscript is accepted. \\ Dedicated to the elegant and stimulating realizations of Professor D. Enders in the field of this review.
}

\begin{abstract}
Polysubstituted chiral cyclohexanes and cyclohexenes are important building blocks in organic synthesis. From historical and pioneer reports to the most recent accounts, this review focuses on domino enantioselective organocatalytic methodologies that have allowed the control of the relative and absolute configurations of up to six stereogenic centers in the construction of these versatile molecular architectures.
\end{abstract}

1. Introduction

2. Two-component transformations

2.1. Michael-initiated domino reactions with $\alpha, \beta-$ unsaturated carbonyl compounds

2.2. Michael-initiated domino reactions with nitroolefins

2.3. Non Michael-initiated domino reactions

3. Multicomponent and related transformations

3.1. Pseudo three-component reactions

3.1.1. Michael-initiated domino reactions with nitroolefins

3.1.2. Michael-initiated domino reactions with $\alpha, \beta$-unsaturated carbonyl compounds

3.2. Consecutive reactions

3.2.1. Michael-initiated domino reactions with nitroolefins

3.2.2. Michael-initiated domino reactions with $\alpha, \beta$-unsaturated carbonyl compounds

3.3. Multicomponent reactions

3.3.1. Michael-initiated domino reactions with nitroolefins

3.3.2. Michael-initiated domino reactions with $\alpha, \beta$-unsaturated carbonyl compounds

4. Conclusion

Key words: organocatalysis, domino reactions, multicomponent reactions, cyclohexanes, cyclohexenes, asymmetric synthesis

\section{Introduction}

In 1858, when Kekulé ${ }^{1}$ and Couper, ${ }^{2}$ independently, discovered the possible connectivity of carbon atoms to form rings, they could not have suspected the importance of carbocyclic structures in modern synthetic organic chemistry. Among these, nonaromatic six-membered carbocycles have generated a particular excitement resulting in a continual renewal of interest worldwide. ${ }^{3}$ From the first synthesis of cyclohexane starting with pimelic acid in $1894,{ }_{5}^{4}$ up to the discovery of the Diels-Alder cycloaddition $^{5}$ and the Robinson annulation ${ }^{6}$ to form functionalized cyclohexenes, both awarded by a Nobel prize in 1947 and 1950, respectively, the ubiquity of six-membered rings in nature ${ }^{7}$ has led to the development of inventive stereoselective synthetic methods.

Nowadays, although the concerted cycloaddition approach largely leads the way, ${ }^{8}$ domino cycloalkylations have emerged more recently as useful complementary strategies, especially by the exponential development of organocatalysis. Based on the pioneer proline-catalyzed enantioselective aldol reaction, first developed in the early 1970s independently by Weichert ${ }^{9}$ and Hajos ${ }^{10}$ groups, the first asymmetric domino Robinson annulation was proposed by Bui and Barbas only in 2000. ${ }^{11}$ Among a large series of pyrrolidine-like amino catalysts, (L)proline (1) gave the best result when methyl vinyl ketone was reacted with 2-methyl-1,3-cyclohexadione leading to the expected Wieland-Miescher ketone $\mathbf{2}$ in $49 \%$ yield and $76 \%$ ee (Scheme 1 ).

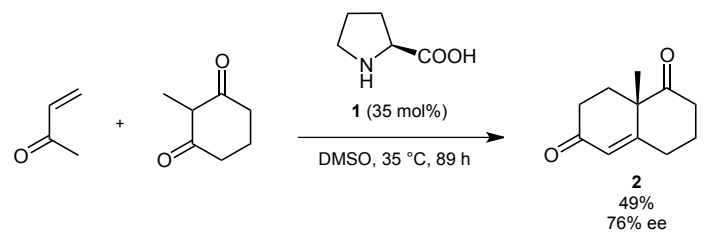

Scheme 1. Domino Robinson annulation for the synthesis of Wieland-Miescher ketone

A few years latter, the same group ${ }^{12}$ reported the first three-component organocatalytic asymmetric domino Knoevenagel-Diels-Alder reaction ${ }^{13}$ for the diastereoand enantioselective construction of highly substituted spiro[5,5] undecane-1,5,9-triones 4 (Scheme 2). (R)5,5-Dimethyl thiazolidine-4-carboxylic acid (DMTC, 3) proved to be the best catalyst allowing to reach the highest yields and stereoselectivities starting with simple unsaturated ketones, aldehydes and Meldrum's acid. 


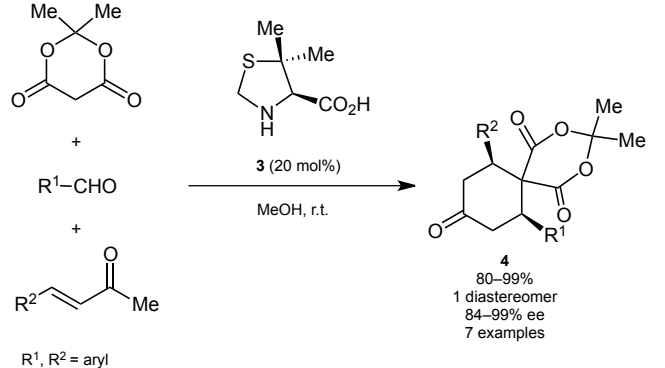

Scheme 2. Three-component enantioselective domino Knoevenagel-Diels-Alder reaction for the synthesis of spiro cyclohexanones

The feasibility of these archetypal organocatalyzed sequences have inspired many research groups over the world contributing to the development of new powerful stereoselective synthesis of polyfunctionalized six-membered rings. This review will comprehensively cover enantioselective organocatalyzed cascade approaches involving either standard bimolecular transformations or more elaborated multicomponent reactions (MCRs) for the construction of highly functionalized cyclohexanes and cyclohexenes. ${ }^{14}$ A special emphasize will be given to multiple bond-forming domino transformations ${ }^{15}$ initiated by Michael additions onto simple $\alpha, \beta$-unsaturated carbonyl compounds or nitroolefins.

\section{Two-component transformations}

Among the diversity of organocatalytic transformations, the development of enantioselective Michael additions ${ }^{16}$ with $\alpha, \beta$-unsaturated carbonyl compounds has received a special attention since its discovery by Yamaguchi and co-workers in 1991 using proline salts. ${ }^{17}$ Twelve years latter, Jørgensen's group $^{18}$ reported a new efficient phenyl alaninederived catalyst for iminium activation of acyclic enones toward the conjugate addition of malonates. Alternatively, nitroolefins are probably the most prominent Michael acceptors, because of their high electrophilicity associated to the synthetic versatility of the nitro function. ${ }^{19}$ Although they have been known for long time, the first asymmetric enamine activation for intermolecular Michael reaction was developed and conceptualized by List et al. in $2001 .^{20}$ These important breakthroughs have opened up the way to the recent development of elegant enantioselective Michael addition-initiated domino transformations with $\alpha, \beta$-unsaturated carbonyl compounds or nitroolefins as well as other related high-order cascades not involving a Michael initiation that are presented in the following three subsections.

\subsection{Michael-initiated domino reactions with $\alpha, \beta$-unsaturated carbonyl compounds}

In 2004, Jørgensen and co-workers reported the synthesis of substituted cyclohexanones $\mathbf{6}$ using an elegant enantioselective domino Michael-aldol transformation from $\beta$-ketoesters and $\alpha, \beta$-unsaturated ketones in the presence of imidazoline organocatalyst 5 (Scheme 3). ${ }^{21}$ The reaction proceeded for various aromatic and heteroaromatic starting materials and proved to be highly diastereoselective producing the six-membered ring possessing all large substituents in equatorial position. The same year, they extended this domino reaction to $\beta$-diketones and $\beta$-ketosulfones with similar efficiencies. ${ }^{22}$

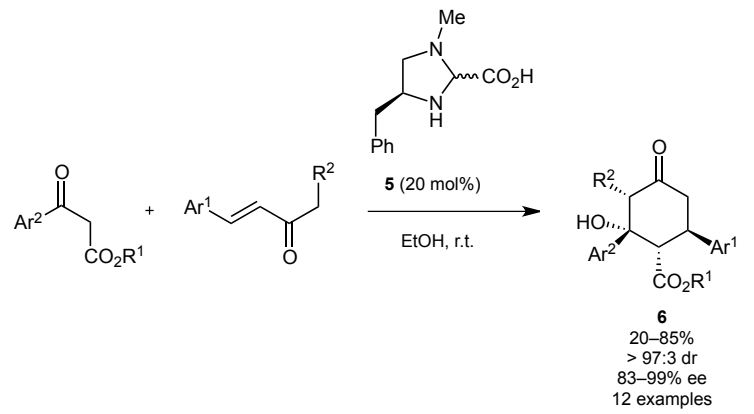

Scheme 3. Domino Michael-aldol for the synthesis of cyclohexanones

An organocatalytic cascade involving an enantioselective Michael addition, followed by a Knoevenagel condensation between $\alpha, \beta$-unsaturated aldehydes and dimethyl-3-oxopentadioate (7) was successfully developed by Hayashi's group in 2009 (Scheme 4). ${ }^{23}$ This formal [3+3]-carbocycloaddition catalyzed by diphenylprolinol derivative 8 allows the enantioselective access to cyclohexenones which are not isolated but treated with sodium borohydride to give the corresponding saturated cyclohexanols 9 with good yields in two consecutive steps. Several aromatic or heteroaromatic conjugated aldehydes were used, affording the desired products with excellent enantioselectivities.

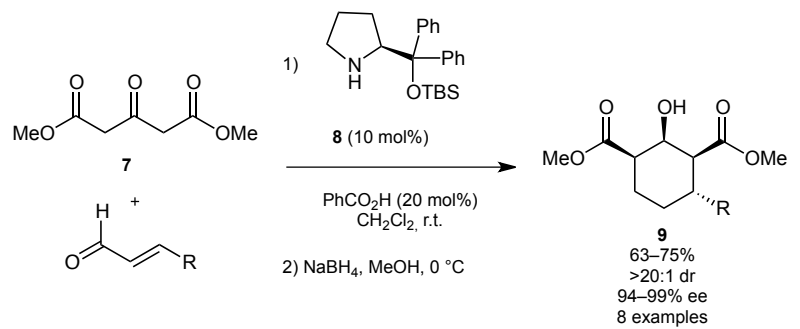

Scheme 4. Organocatalytic enantioselective MichaelKnoevenagel cascade

This work is related to a sequence developed earlier by the group of Jørgensen for the enantioselective synthesis of chiral cyclohexenones $\mathbf{1 1}$ from tert-butyl3 -oxobutyrate and $\alpha, \beta$-unsaturated aldehydes catalyzed by a diphenylprolinol silyl ether derivative 10 (Scheme 5). ${ }^{24}$ In this consecutive reaction, while the chiral organocatalyst promotes the enantioselective Michael addition, paratoluenesulfonic acid ( $p$-TSA) catalyzes the hydrolysis of the ester function and promotes the decarboxylation 
of the resulting ketoacid intermediate. It is also responsible of the aldol and elimination steps furnishing the cyclohexenones $\mathbf{1 1}$ in good yields and excellent enantioselectivities.

A similar Michael/aldol/dehydration reaction was reported by Zhao and co-workers reaction between benzoylacetates and $\alpha, \beta$-unsaturated ketones to provide functionalized chiral cyclohexenones in excellent yields and enantioselectivities and moderate diastereoselectivities. ${ }^{25}$

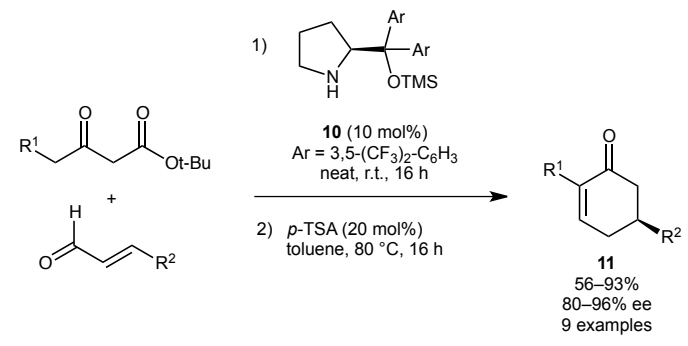

Scheme 5. Michael-aldol cascade for the synthesis of cyclohexanones

The asymmetric synthesis of epoxycyclohexanones 15 bearing three stereogenic centers has been accomplished by Jørgensen and co-workers in 2006 who reported a Michael-aldol-intramolecular $\mathrm{S}_{\mathrm{N}} 2$ organocatalytic cascade between enal and $\gamma$-chloro- $\beta$ ketoesters 12 (Scheme 6). ${ }^{26}$ The enantioselective Michael addition is catalyzed by the prolinol derivative followed by an aldol reaction due to the presence of sodium acetate acting as a base. In a consecutive step, the addition of a stronger base $\left(\mathrm{K}_{2} \mathrm{CO}_{3}\right)$ deprotonates the alcohol 13 and enables the intramolecular $\mathrm{S}_{\mathrm{N}} 2$ reaction to lead to the formation of the epoxide 14 via a two-step Darzens condensation. Saponification of the ester function of $\mathbf{1 4}$ followed by decarboxylation gives the compounds $\mathbf{1 5}$ as virtually single stereoisomers.

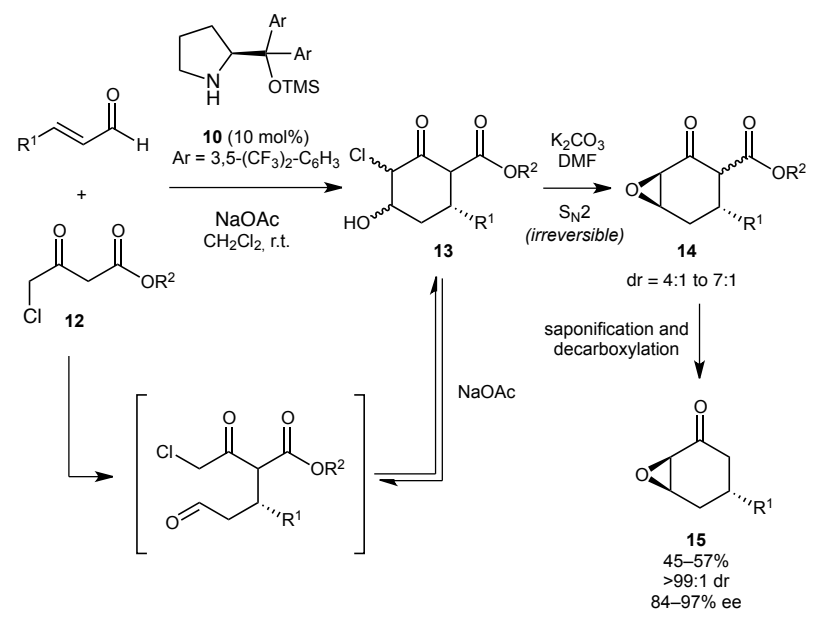

Scheme 6. Organocatalytic Enantioselective Michael-Darzens cascade

Enantioenriched bicyclo[3.3.1]nonane products 19 were synthesized by the group of Tang who reported a formal [3+3] annulation between cyclic ketones 16 and activated enones 17 (Scheme 7). ${ }^{27}$ Hence, pyrrolidine derivative $\mathbf{1 8}$ is capable of promoting a domino Michael-aldol reaction providing the final 2hydroxy-9-oxobicyclo[3.3.1]nonanes $\mathbf{1 9}$ with four stereocenters in moderate to good yields and with good to high enantioselectivities under mild conditions.

In the same vein, Liu and co-workers described in 2008 one example of an enantioselective organocatalytic domino Michael-aldol reaction between acetone and $\alpha, \beta$-unsaturated trifluoromethyl ketone, albeit with moderate success. ${ }^{28}$ They also demonstrated the possibility of accessing bicyclic products similar to $\mathbf{1 9}$, in the racemic series, displaying a trifluoromethyl moiety instead of the ester group.
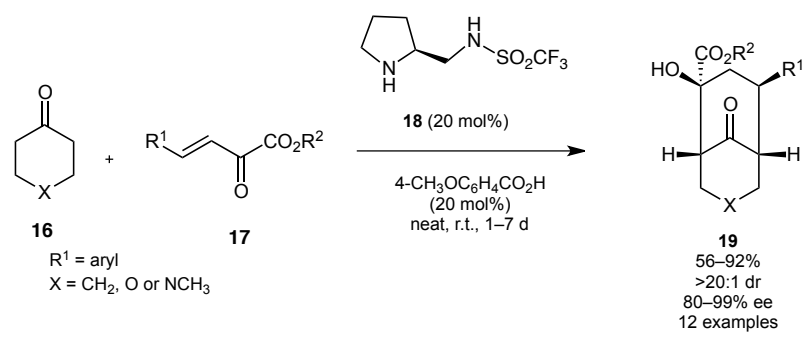

Scheme 7. Optically active bicyclo[3.3.1]nonane synthesis

In 2010, the group of Carter reported a Michaelaldol-dehydration cascade for the construction of cyclohexenone derivatives $\mathbf{2 1}$ bearing two contiguous stereogenic centers, one of which being a quaternary carbon at the 4-position (Scheme 8). ${ }^{29}$ A novel sulfonamide organocatalyst $\mathbf{2 0}$ was developed for an efficient iminium-enamine activation mode and the desired cyclohexenones $\mathbf{2 1}$ where obtained in a highly enantio- and diastereoselective fashion in generally good chemical yield. Simultaneously, Kotsuki and coworkers described a very similar Robinson-type annulation giving rise to analogous cyclohexenones lacking the tertiary stereogenic center. ${ }^{30}$ They employed a chiral diamine/dicarboxylic acid system for catalyzing this domino reaction, which was applied to the synthesis of $(+)$-sporochnol A.

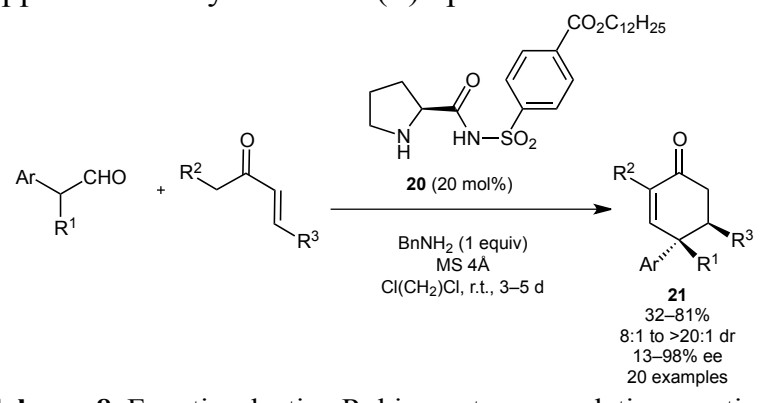

Scheme 8. Enantioselective Robinson-type annulation reaction

Based on the potential dual reactivity of dialdehydes, a highly enantioselective organocatalytic domino Michael/aldol reaction has been reported by the group of Córdova between glutaraldehyde as pronucleophile and electrophile and 2-cyanocinnamic acid esters 22 as Michael acceptors. The reaction is catalyzed by 
diphenylprolinol silyl ether $\mathbf{2 3}$ and gives access in high yields and good stereoselectivities to highly functionalized cyclohexanols $\mathbf{2 4}$ bearing one allcarbon quaternary stereocenter in high yields and good stereoselectivities. This reaction was initially developed by Hayashi et al. with nitroalkenes as Michael acceptors (vide infra, Scheme 35) which provided superior diastereoselectivities in the final carbocycles. ${ }^{31}$

$$
\text { (2) }
$$

Scheme 9. Domino Michael-Henry reaction for the synthesis of cyclohexanols

Nitroalkenes also constitute very powerful pronucleophiles and in this context, Enders et al. reported a complementary Michael-aldol-dehydration cascade reaction between acyclic $\gamma$-nitroketones $\mathbf{2 5}$ and enals under iminium/enamine activation. Diphenylprolinol silyl ether $\mathbf{2 3}$ organocatalyst allowed the synthesis of optically active trisubstituted cyclohexene carbaldehydes $\mathbf{2 6}$ in moderate yields and good selectivities (Scheme 10). ${ }^{32}$ Two years later, they showed the possibility of using 2-(nitromethyl) benzaldehyde instead of the $\gamma$-nitroketones, which afforded the corresponding functionalized 3,4dihydronaphthalenes in moderate yields and excellent stereoselectivities. $^{33}$

$$
\text { (25 }
$$

Scheme 10. Michael-aldol-dehydration cascade for the synthesis of optically active cyclohexene carbaldehydes

An extension of this approach concerns the efficient synthesis of enantiomerically enriched [4.4.0]decane bicyclic carbon frameworks reported by Chen's group who used the same diphenylprolinol silyl ether $\mathbf{2 3}$ to catalyze a nitro-Michael-aldol cascade between optically active $\gamma$-nitrocycloalkanones 27 and enals (Scheme 11). ${ }^{34}$ The authors clearly demonstrated the crucial role of the catalyst (iminium-enamine activation) and showed that the reaction was not under substrate control. The hexa-substituted decalin carboxaldehydes $\mathbf{2 8}$ were obtained in good yields with excellent diastereo- and enantioselectivities.

$$
\text { (27 }
$$

Scheme 11. Optically active bicyclo[4.4.0]decanols synthesis

Simple acyclic 1,3-dinitroalkanes were employed as efficient bis-pronucleophiles by Jørgensen and coworkers in an organocatalyzed enantioselective Michael-Henry cascade for the access to tetrasubstitued cyclohexanols $\mathbf{2 9}$ displaying five stereogenic centers (Scheme 12). ${ }^{35}$ The best catalytic system was found to be the diphenylprolinol silyl ether derivative $\mathbf{1 0}$ in combination with 1,4diazabicyclo[2.2.2] octane (DABCO). The enal is activated as an iminium ion undergoing nucleophilic additions of the nitroalkane from the less hindered face. The final intramolecular Henry reaction is proceeding without catalyst involvement.

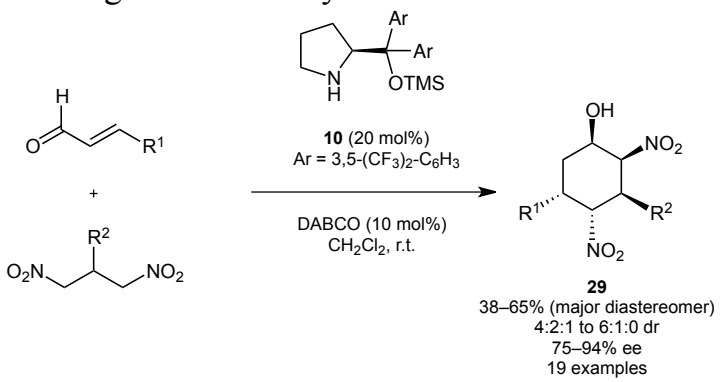

Scheme 12. Domino Michael-Henry reaction for the synthesis of cyclohexanols

In 2011, based on the reactivity of unsaturated sulfones, the group of Alexakis introduced a conceptually new access to cyclohexadienes 32, in which the initial 1,4-addition of the domino reaction is replaced by a 1,6 -addition (Scheme 13$){ }^{36}$ The rational design of substrates $\mathbf{3 0}$ containing a diene activated by two sulfones in positions 1 and 3 was the key to the success. Their cooperative activating effects guides the regioselectivity of the addition of an enamine formed by the condensation of an enolizable aldehyde with Hayashi-Jørgensen catalyst 31. A subsequent trapping of the iminium by the delocalized anion stabilized by the two sulfones followed by catalyst release by elimination yielded the desired products in impressive diastereo- and enantioselectivities.
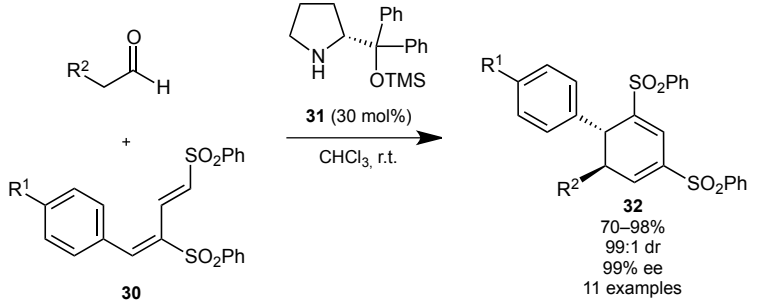
Scheme 13. Domino 1-6-conjugate addition-cyclizationelimination for the synthesis of cyclic 1,3-dienes

The combination of several Michael addition steps in a domino sequence represents an efficient strategy to elaborate complex structures. Since these transformations create $\mathrm{C}-\mathrm{C}$ bonds, they are suitable tools to assemble carbocycles, including cyclohexanes and their partially unsaturated analogues.

It has been known for several years that diarylprolinol trimethylsilyl ethers can efficiently catalyze the Michael addition of 1,3-dicarbonyls to $\alpha, \beta$-unsaturated aldehydes via iminium activation. ${ }^{37,38}$ When one of the carbonyl groups of the pronucleophile is substituted with an alkene (these substrates are often referred to as Nazarov reagents), one can envisage that the enamine resulting from the initial addition adds to this electron-poor olefin to affording a cyclohexanone. However, when the group of Jørgensen investigated this transformation with unsubstituted enones, they were surprised to obtain exo-methylenecyclohexenes 33 with very good stereoselectivities (Scheme 14). ${ }^{39}$ The formation of these products is believed to occur via a Michael addition followed by an intramolecular Morita-Baylis-Hillman reaction.
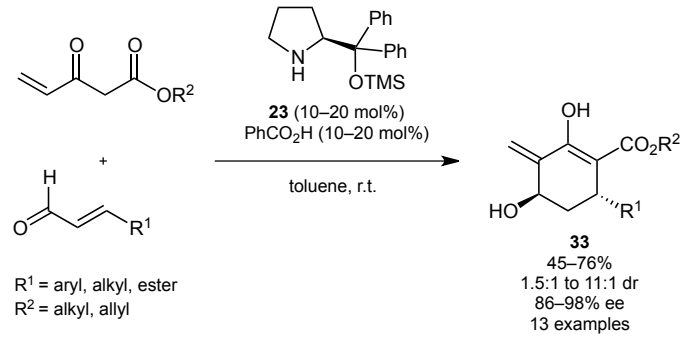

Scheme 14. Synthesis of exo-methylenecyclohexanones by a Michael-Morita-Baylis-Hillman domino reaction

In 2009, McGarraugh and Brenner recognized that using 1,3-dicarbonyls functionalized with (hetero)cyclic alkenes could divert the aforementioned reaction pathway and also other competitive reaction to prepare the polyfunctionalized cyclohexanones 34, under their enol form (Scheme 15). ${ }^{40}$ The use of alcoholic solvents, and more specifically the strong hydrogen bond donor trifluoroethanol, was essential to ensure good conversions, especially by speeding up the second Michael addtion. Products were thus obtained in good yields with high diastereoselectivities and excellent enantioselectivities. With this improved understanding of the catalytic cycle, the same authors could extend this reactivity to both alkyl- and aryl-substituted linear substrates. ${ }^{41}$

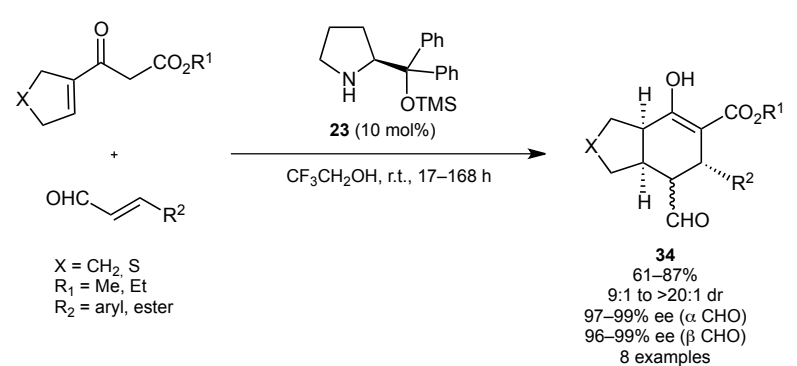

Scheme 15. Michael-Michael domino reactions using 1,3ketoesters substituted with a cyclic alkene.

This reactivity pattern has since then been extended to other functionalized pronucleophiles. In 2011, Hong and co-workers showed that $\alpha, \beta$-unsaturated esters that bear a pendant aldehyde could be combined with enals to afford cyclohexanes $\mathbf{3 5}$ with the complete control of the four stereogenic centers created in the transformation (Scheme 16). ${ }^{42}$ The combination of Hayashi-Jørgensen catalyst $\mathbf{2 3}$ and $\mathrm{AcOH}$ in acetonitrile was required to ensure a good turnover and to obtain high yields. Several postfunctionalizations of the products were studied, including their reaction with a 2.5 -fold excess of racemic serine methyl ester. Perfect kinetic diastereoselection was observed and the tricyclic product $\mathbf{3 6}$ was obtained as the sole stereoisomer.
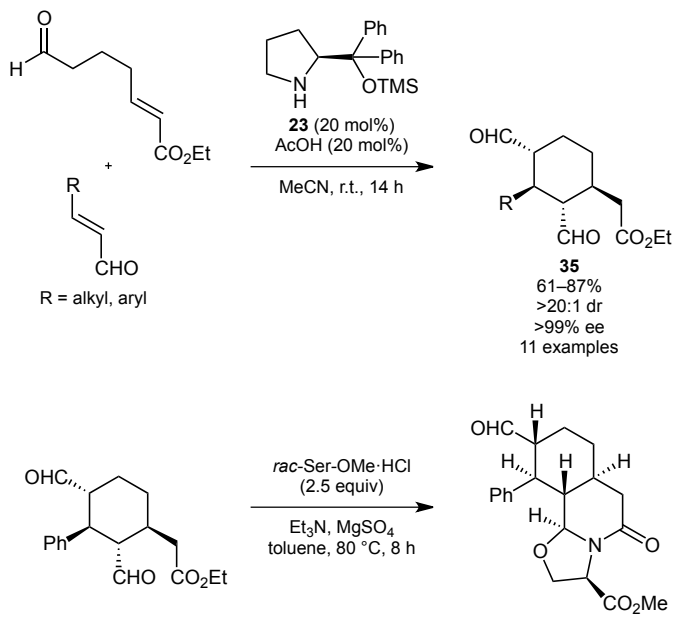

36, $68 \%$

Scheme 16. Synthesis of functionalized cyclohexanes by reaction of $\omega$-oxo- $\alpha, \beta$-unsubstituted esters with enals

With 1,3-dicarbonyls and aldehydes, nitro derivatives are also one of the most widely used families of pronucleophiles in organocatalysis. Reacting moderately enantioenriched nitro-substituted $\alpha, \beta$ unsaturated esters with cinnamaldehyde derivatives in the presence of the classic combination of catalyst $\mathbf{2 3}$ and $\mathrm{AcOH}$ afforded in moderate yields cyclohexanes 37 bearing five contiguous stereogenic centers as a mixture of two diastereomers (Scheme 17). ${ }^{43}$ The anti isomer was predominantly formed with diastereomeric ratios around 6:1. After reduction of the unstable aldehyde to the alcohol, enantiomeric excesses were determined to be very good. 


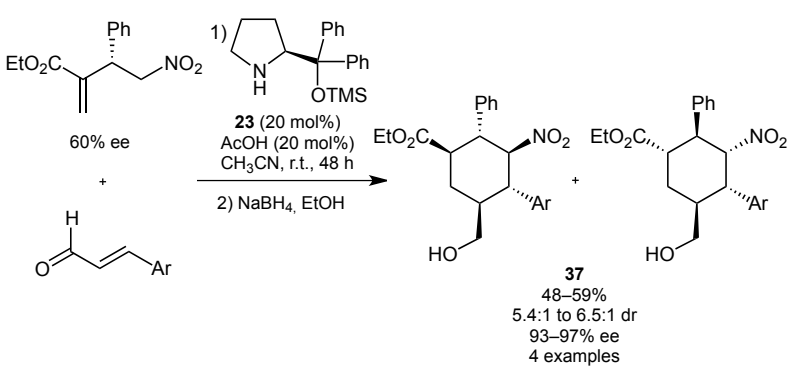

Scheme 17. Synthesis of functionalized cyclohexanes by reaction of unsaturated nitroesters with enals.

Very recently, linear $\omega$-nitro- $\alpha, \beta$-unsaturated esters $\mathbf{3 8}$ were also involved in a related transformation (Scheme 18). ${ }^{44}$ The cyclohexanes 39 were obtained using Hayashi-Jørgensen pyrrolidine $\mathbf{2 3}$ and DABCO catalyst combination. They were not isolated but reacted in situ with tryptamine derivatives $\mathbf{4 0}$ in the presence of TFA in refluxing toluene to afford the "inside yohimbane" scaffold 41, which contains five stereogenic centers, in almost perfect stereoselectivities.
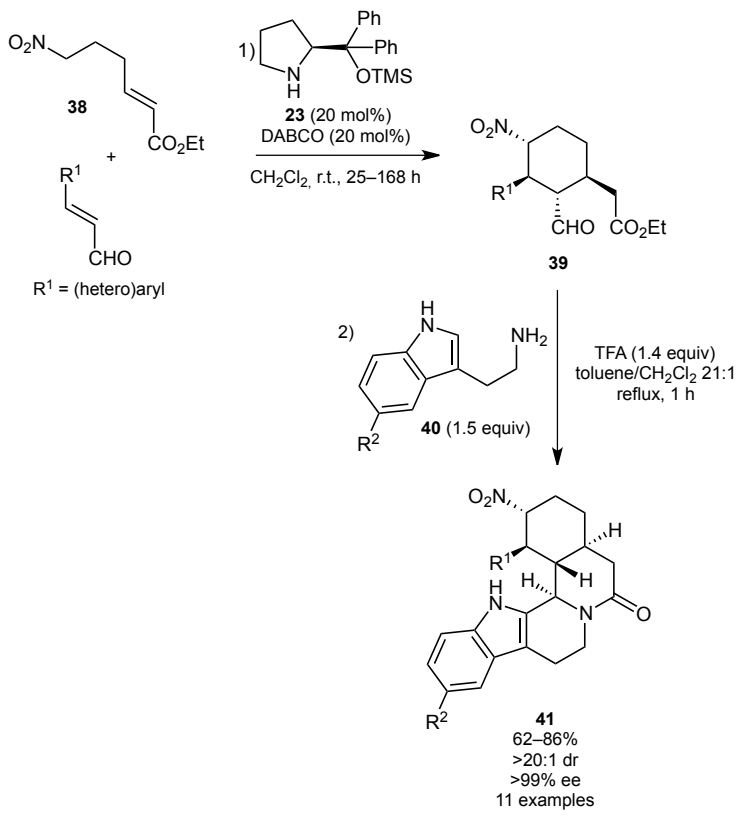

Scheme 18. Synthesis of functionalized cyclohexanes by reaction of $\omega$-nitro- $\alpha, \beta$-unsaturated esters with enals and subsequent cascade reaction with tryptamine derivatives

Other electrophiles than enals can be used to prepare functionalized cyclohexanes by organocatalyzed Michael-Michael domino sequences. For example, pronucleophile $\mathbf{3 8}$ previously depicted above can also be combined with $\alpha, \beta$-unsaturated cyanosulfones in the presence of the bifunctional thiourea-tertiary amine catalyst 42 (Scheme 19). ${ }^{45}$ The highly functionalized cyclohexanes $\mathbf{4 3}$ that bear four contiguous stereogenic centers are obtained with interesting enantioselectivites that could even be improved by recrystallization.

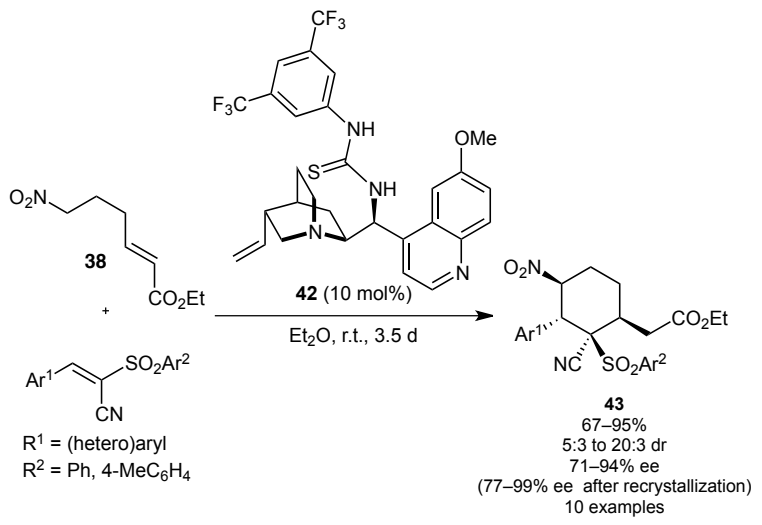

Scheme 19. Synthesis of functionalized cyclohexanes by reaction of $\omega$-nitro- $\alpha, \beta$-unsaturated esters with $\alpha, \beta$-unsaturated cyanosulfones

Like enals, enones can also be activated towards Michael addition via iminium ion intermediates and the enantioselectivity of this process can be controlled by the use of a chiral amine in catalytic amount. However, because of higher steric hindrance, primary amines such as $\mathbf{4 4}$ are generally preferred to secondary amine for the activation of enones. During their studies on the Michael addition of $\alpha, \alpha$ dicyanoalkenes on enones, Deng and co-workers observed for some substrates cascade reactions that afforded cyclohexane and cyclohexene derivatives $\mathbf{4 5}$ and 46 (Scheme 20). ${ }^{46}$ Activation of the $\gamma$ position of the $\alpha, \alpha$-dicyanoalkenes triggered a Michael-enolate migration-Michael sequence to yield products $\mathbf{4 5}$ with a high enantioselectivity. When open-chain dicyanoalkenes were used, cyclohexenes 46 were isolated because of a retro-Michael reaction at the end of the cascade. Besides this, the second Michael addition did not achieve completion and linear adducts 47 were also obtained. Notably, kinetic resolution occurred during the second Michael addition as the cyclic products were obtained with higher enantioselectivities as the simple Michael adducts. 

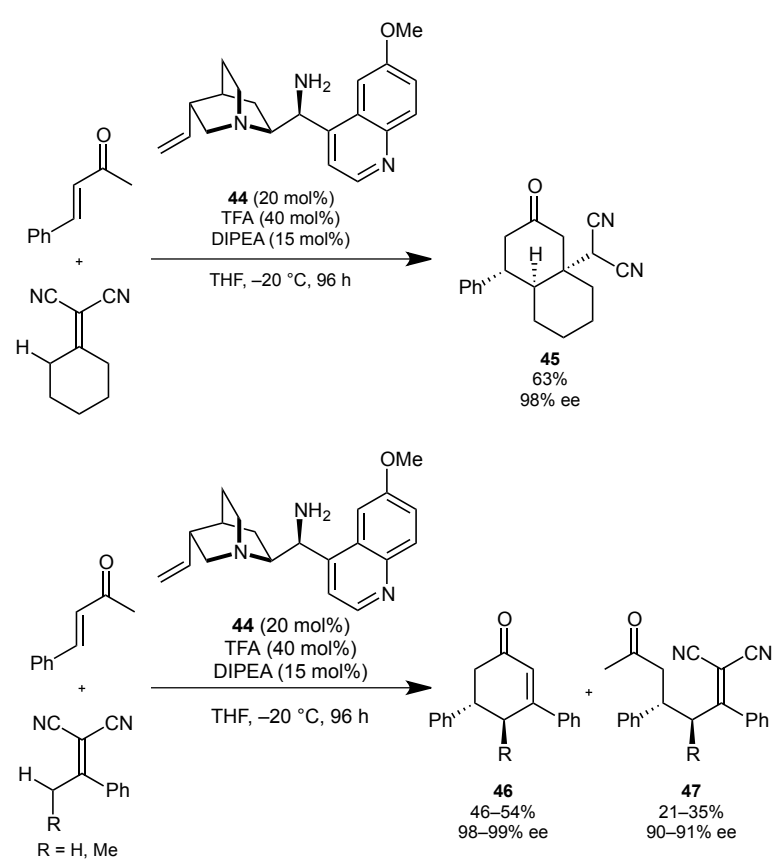

Scheme 20. Synthesis of enantioenriched six-membered carbocycles from enones and $\alpha, \alpha$-dicyanoalkenes

In 2008, the group of Melchiorre introduced primary amine catalyst 48 , which derives from a cinchona alkaloid, as a very versatile catalyst that can notably activate efficiently $\alpha^{\prime}$-alkylenones as enamines. ${ }^{47}$ In the presence of 2-fluorobenzoic acid as a co-catalyst, these enamines could undergo a Michael addition with different electron-poor olefins, such as $(E)-\alpha$ cyanocinnamate and maleimides (Scheme 21). ${ }^{48} \mathrm{An}$ intramolecular Michael addition on the resulting $\alpha, \beta$ unsaturated iminium followed by catalyst release afforded cyclohexanones $\mathbf{4 9}$ and $\mathbf{5 0}$ in high yields and with excellent stereoselectivities.

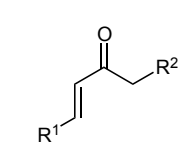

$\mathrm{R}^{1}=$ (hetero)aryl, ester $\mathrm{R}^{2}=\mathrm{H}, \mathrm{Me}$<smiles>CCOC(=O)/C(C#N)=C/c1ccccc1</smiles><smiles>[R]C=CC(C)=O</smiles>

$\mathrm{R}^{1}=$ (hetero)aryl

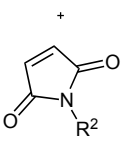

$\mathrm{R}^{2}=\mathrm{Ph}, \mathrm{Bn}$
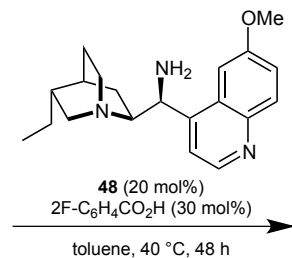

toluene, $40^{\circ} \mathrm{C}, 48 \mathrm{~h}$
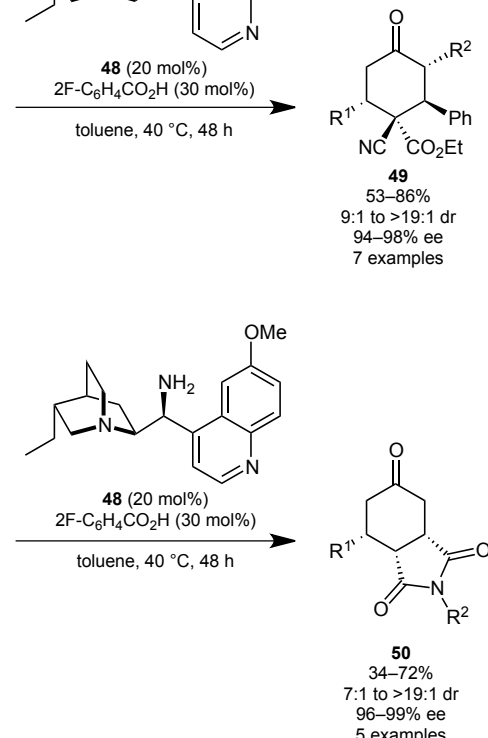

Scheme 21. Primary amine-catalyzed Michael-Michael domino reactions of $\alpha^{\prime}$-alkylenones with $(E)$ - $\alpha$-cyanocinnamate and maleimides
A similar strategy was implemented with 3alkenylidene oxindoles as the electrophilic coupling partners (Scheme 22). ${ }^{49}$ Annulation occurred under very similar reaction conditions, providing a synthetic access to biologically-relevant enantioenriched spirooxindoles 51. Variations on four different positions of the starting materials demonstrated the wide applicability of this domino process. In addition to this, the use of cyclohexenones in this transformation resulted in the formation of a bicyclo[2.2.2] octane motif spiroannulated to the oxindole. Although lower yields of product $\mathbf{5 2}$ were obtained, the fast elaboration of such molecular complexity from readily available starting materials, along with the possibility to create two contiguous quaternary stereocenters, establishes this transformation as a highlight among organocatalyzed domino reactions.
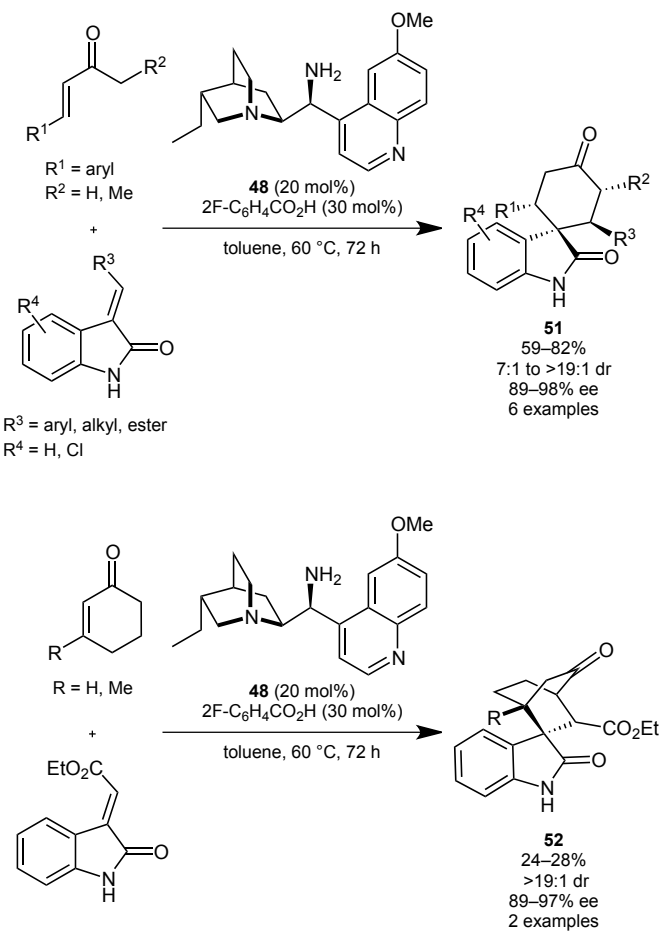

Scheme 22. Synthesis of spiro-oxindoles via a primary-amine catalyzed Michael-Michael domino reaction

The same reactivity pathway can also be applied to the synthesis of the spiro-benzofuranones 53, which constitute the backbone of several natural products such as rosmadial and hopeahainol A (Scheme 23). ${ }^{50}$ Once again, high enantioselectivities were obtained but diastereoselectivities remained moderate, except for an alkylidene benzofuranone. Recently, it was also reported that the same strategy can be used to prepare spiro-pyrazolones with a very similar catalytic system. ${ }^{51}$ 


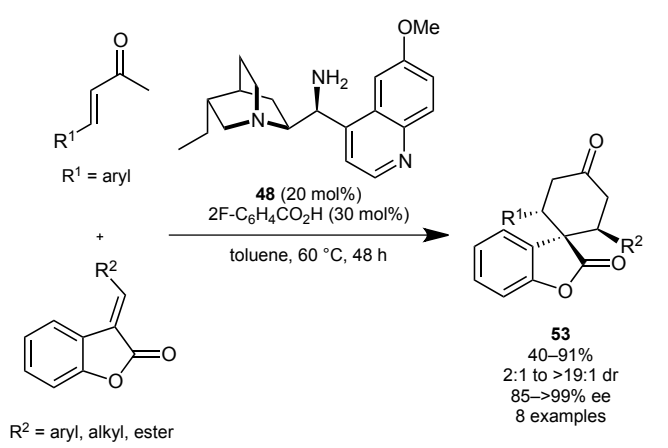

Scheme 23. Synthesis of spiro-benzofuranones via a primaryamine catalyzed Michael-Michael domino reaction

When the ketone used in the previous sequence was replaced by a $\beta$-ketoester, a different catalytic activation mode was required: in this case, hydrogenbonding was found to be more efficient that enamine formation (Scheme 24). ${ }^{52}$ With bifunctional urea 54, related products $\mathbf{5 5}$ were formed with very good stereoselectivities. A noticeable difference with the reaction developed by Melchiorre ${ }^{49}$ is that $N$-acyl indole substrates were performing at best in this case.
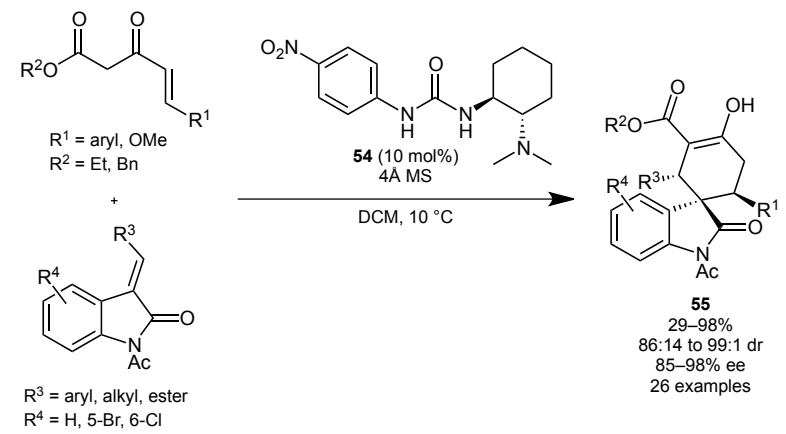

Scheme 24. Synthesis of spiro-oxindoles via a bifunctional urea-tertiary amine-catalyzed Michael-Michael domino reaction

A complementary strategy to prepare spirocyclohexanones consists in the formal [5+1] cycloaddition between a dienone and a pronucleophile, via a Michael-Michael domino reaction. The groups of Yan and Lattanzi independantly reported the double Michael addition of malonitrile to dienones. ${ }^{53}$ The former group achieved high enantiomeric excesses with 9-amino-9deoxyepiquinine $\mathbf{4 4}$ as the catalyst (Scheme 25) whereas selectivities remained moderate in the studies of the second group with quinine as the catalyst. The nitrile group could also be replaced by other electron withdrawing groups such as nitro, esters or ketones.

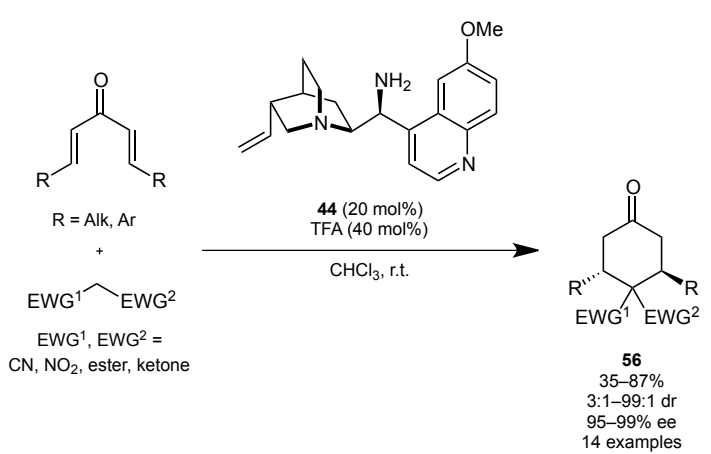

Scheme 25. Synthesis of cyclohexanones via a formal [5+1] cycloaddition between dienones and active methylene derivatives

Nitromethane was also used as pronucleophile in a related transformation but the two steps had to be performed stepwise. ${ }^{54}$ Heterocycles such as protected oxindoles are also potent pronucleophiles in these formal [5+1] cycloadditions, affording the expected spiro-oxindoles with good yields and selectivities (Scheme 26). ${ }^{55}$ It is worth noting that the symmetry of the dienone is helpful to prevent regioselectivity problems and also allows achieving high diastereoselectivities. (S)-BINOL-phosphoric acid $\mathbf{5 7}$ was found to be superior to other acid co-catalysts in the presence of primary amine catalyst $\mathbf{4 4}$ for this reaction in terms of enantioselectivity. However, this seems to be linked to its acidity rather than to its axial chirality, as its enantiomer was affording the product 58 with identical enantiomeric excess, albeit with reduced yield. This reactivity pattern was then implemented on other pronucleophiles such as pyrazolones and benzofuranones. ${ }^{56}$

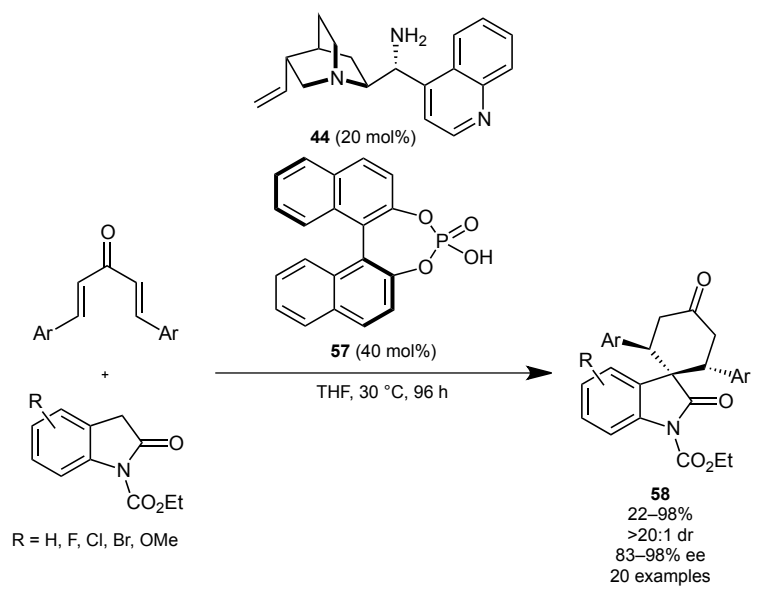

Scheme 26. Synthesis of spiro-oxindoles via a formal [5+1] cycloadditions

The activation of aldehydes by $N$-heterocyclic carbenes (NHCs) proceeds via a unique activation mode that results in the umpolung of the carbonyl group, which behaves as an acyl anion equivalent. ${ }^{57}$ When enals are used, the nucleophilic properties transfer to the $\beta$ position and the activated intermediates are termed as homoenolates. ${ }^{58}$ In 2011, Chi and co-workers combined enals with bis-enones in the presence of the chiral triazolium salt precatalyst 
59 (Scheme 27). ${ }^{59}$ The domino sequence consisted of a first Michael addition of the homoenolate and a second one of the enolate to obtain the benzocyclohexane ring, followed by the lactonization with release of the catalyst. The tricyclic compounds $\mathbf{6 0}$ were formed in good yields and high to very high stereoselectivities. Moreover, when the bis-enones bears two aromatic groups $\mathrm{R}^{1}$ and $\mathrm{R}^{2}$ that are not identical, the first addition occurs preferentially on the more electron-deficient enone moiety, usually with good regioselectivities. Likewise, when $\mathrm{R}^{2}$ is an alkyl substituent, the other enone is the one that undergoes the Michael addition of the homoenolate. In this case, the diastereoselectivity of the whole process is notably decreased.

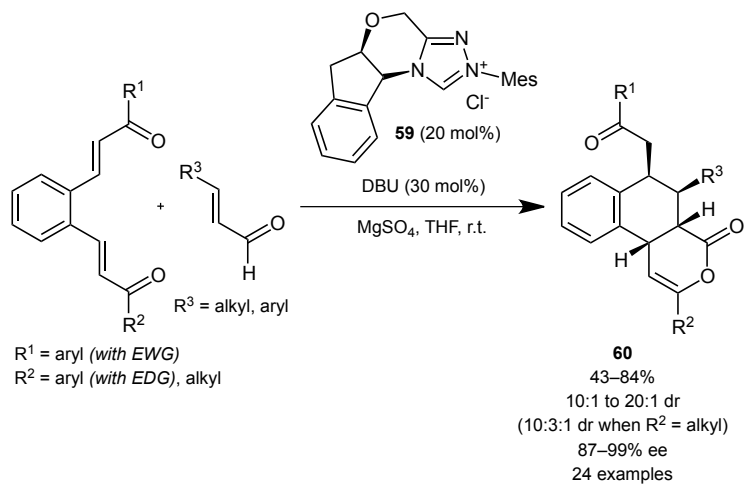

Scheme 27. Synthesis of polycyclic structures by a NHCcatalyzed Michael-Michael-lactonization sequence

\subsection{Michael-initiated domino reactions with nitroolefins}

The first Michael-initiated domino transformation starting from a nitroolefin as acceptor was described by Takemoto and co-workers in $2004 .^{60}$ They used their newly designed bifunctional thiourea 61 to promote, through hydrogen-bonding activation, the asymmetric Michael-Michael transformation between trans- $\beta$-nitrostyrene and ethyl 3-oxohex-4-enoate, providing the expected $\alpha$-carboxycyclohexanones $\mathbf{6 2}$ in $65 \%$ yield and with high diastereo- and enantioselectivity (Scheme 28). However, this reaction constituted the only reported example since no cyclized product could be obtained with other 1,3ketoesters $(\mathrm{R}=\mathrm{Ph}$, OMe, $i$-Pr $)$. However, in these cases, the formation of the corresponding Michael adducts was observed, the second Michael addition step being promoted by subsequent addition of an organic base (tetramethylguanidine) providing the desired cyclohexanones with comparable levels of selectivity.

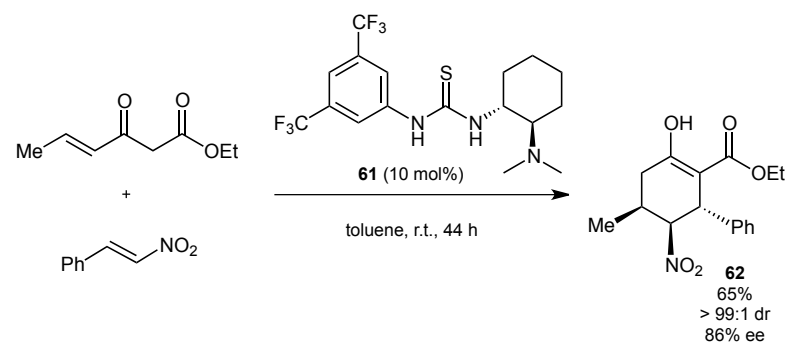

Scheme 28. $\alpha$-Carboxycyclohexanones synthesis by a domino Michael-Michael transformation

In 2009, Melchiorre and co-workers showed that primary amine-based organocatalysts were suitable species for such domino reactions. ${ }^{48}$ Catalytic amounts of 9-amino-9-deoxy-epi-hydroquinine $\mathbf{4 8}$ and 2-fluorobenzoic acid was engaged with acyclic enones and functionalized nitroolefins, allowing the stereoselective formation of cyclohexanones $\mathbf{6 3}$ bearing up to four contiguous stereogenic centers (Scheme 29). The nature of the co-catalyst was important for the outcome of the reaction as both the rate and the diastereoselectivity could be enhanced when salicylic acid was used instead of 2fluorobenzoic acid, albeit with a slight decrease in the enantioselectivity. The reaction mechanism consists in a stepwise Michael-Michael addition sequence in which the catalyst activates the substrates through an enamine-iminium process. The selective formation of the trans-63 product nicely complements the methodology developed by Barbas, who obtained in similar conditions the cis-63 products via a [4+2] cycloaddition. ${ }^{61}$

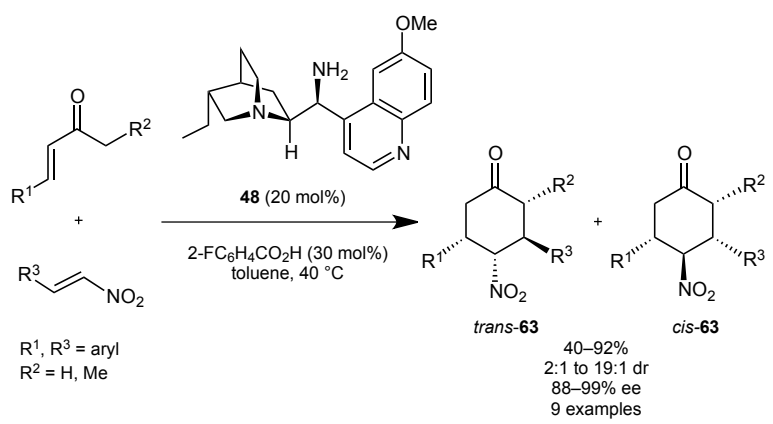

Scheme 29. Cyclohexanones synthesis by a domino MichaelMichael transformation

Two years later, similar reaction conditions were used by the group of Xu in a sequential Michael-MichaelMichael-aldol cascade. ${ }^{62}$ The above primary amine $\mathbf{4 8}$ was employed with 4-nitrobenzoic acid to promote the double Michael domino reaction with acyclic enones and functionalized nitroolefins, affording optically active cyclohexanones. These intermediates were subsequently engaged in a TBAF-mediated intramolecular Michael-aldol domino transformation to access complex tetracyclic structures $\mathbf{6 4}$ in good yields and excellent stereoselectivities (Scheme 30). This one-pot strategy initiated by a Michael-Michael domino transformation allows the formation and 
control of six stereogenic centers, including two quaternary ones.

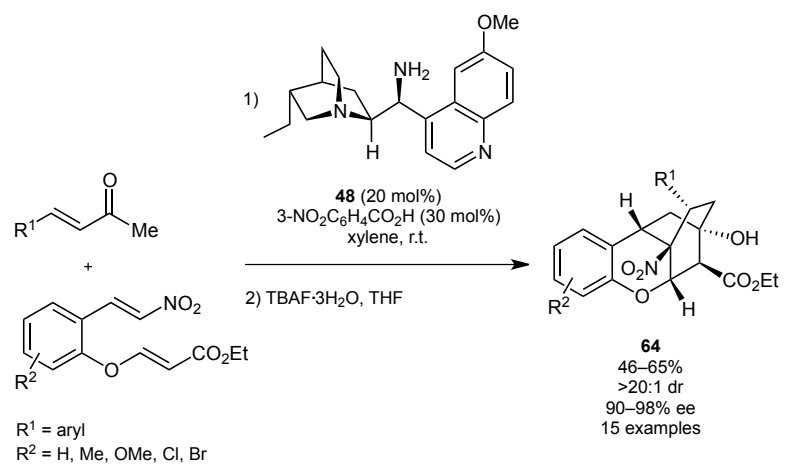

Scheme 30. One-pot Michael-Michael-Michael-aldol for the access of bicylic [2.2.2] ring systems

Very recently, Cobb and co-workers designed an asymmetric domino Michael-Michael reaction between nitrohexenoates $\mathbf{6 5}$ and nitroalkenes to synthesize optically active cyclohexane derivatives $\mathbf{6 6}$ and 67, with a high level of complexity and bearing up to five contiguous stereocenters (Scheme 31). ${ }^{63}$ The bifunctional thiourea-tertiary amine $\mathbf{4 2}$ proved to be the best catalyst for this transformation, affording the desired carbocycles with moderate to excellent yields and stereoselectivities. The methodology could be applied to a wide range of aromatic nitroolefins, including the less reactive trans- $\beta$-methyl- $\beta$ nitrostyrene $\left(\mathrm{R}^{2}=\mathrm{Ph}, \mathrm{R}^{3}=\mathrm{Me}\right)$, which formed the expected cycloadduct displaying a quaternary carbon atom in very high stereoselectivities $(\mathrm{dr}>19: 1$, ee $>$ $99 \%$ ), despite a very low yield (4\%). Trisubstituted nitroenoates $\left(65, \mathrm{R}^{1}=\right.$ alkyl, F) were also used and resulted in the formation of the cyclohexanes 66 with an additional stereogenic centers, albeit lower yields and diastereoselectivies were observed.

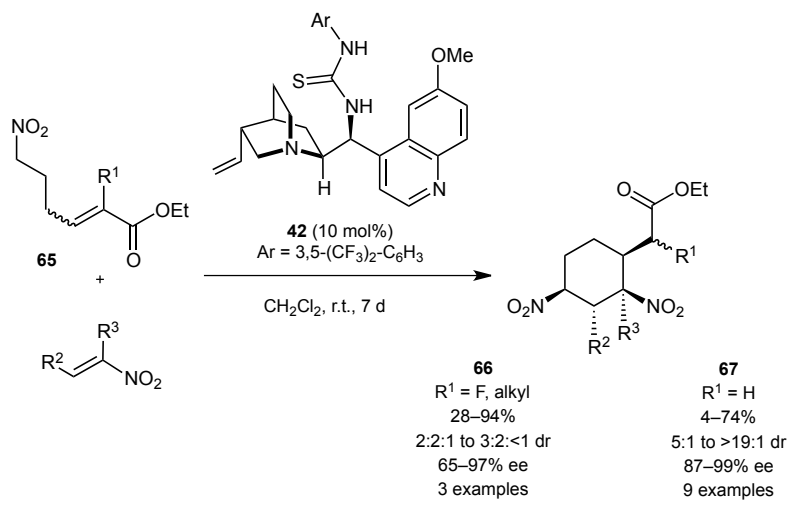

Scheme 31. Double Michael cascade reaction for the synthesis of substituted 1,3-dinitrocyclohexanes

In 2010, the group of Xiao described a MichaelMichael-aromatization cascade of 2-propenylindoles 68 and nitroalkenes by a simple chiral hydrogenbonding donor organocatalyst 69 (Scheme 32). ${ }^{64}$ An initial intermolecular Friedel-Crafts alkylation on the nitroolefin is forming the first $\mathrm{C}-\mathrm{C}$ bond while the other $\mathrm{C}-\mathrm{C}$ bond is the result of a second intramolecular Michael addition of the nitroalkane on the iminium intermediate. Finally, a rapid $[1,3]-H$ migration regenerates the aromaticity of indole ring. This methodology furnished potentially interesting biological active products $\mathbf{7 0}$ with good optical purity but is however limited by the scope on the indole moiety.

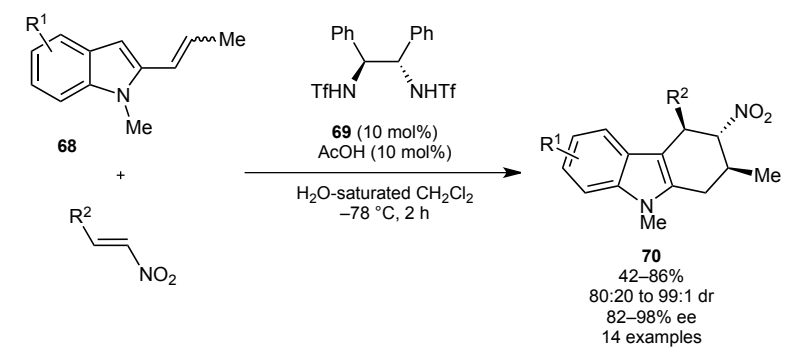

Scheme 32. Enantioselective domino reaction to tetrahydrocarbazole derivatives

The development by Sun and co-workers in 2009 of an enantioselective organocatalyzed Michaelelimination-proton transfer-Michael domino reaction allows the formation of functionalized bicyclo[3.3.1]nonane systems $\mathbf{7 2}$ with good to excellent diastereo- and enantioselectivities (Scheme 33). ${ }^{65}$ In the paper, the authors completed their methodology with theoretical calculations justifying the choice of the organocatalyst $\mathbf{7 1}$, which allowed them to propose a transition state that explains the observed stereoselectivities.

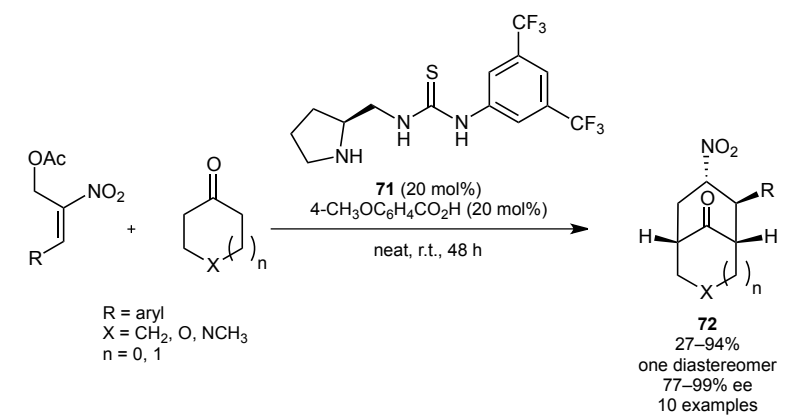

Scheme 33. Cascade Michael-elimination-proton transferMichael for the access to functionalized bicyclo[3.3.1]nonanes

Very recently, Hong et al. reported a complementary access to bicyclo[3.3.1]nonane systems using 3-aryl2-nitropropen-2-ols $\mathbf{7 3}$ and glutaraldehyde. The enantioenriched 3-oxabicyclo[3.3.1]nonan-2-ones $\mathbf{7 4}$ were obtained in good yields and excellent diastereoand enantioselectivities (Scheme 34). ${ }^{66}$
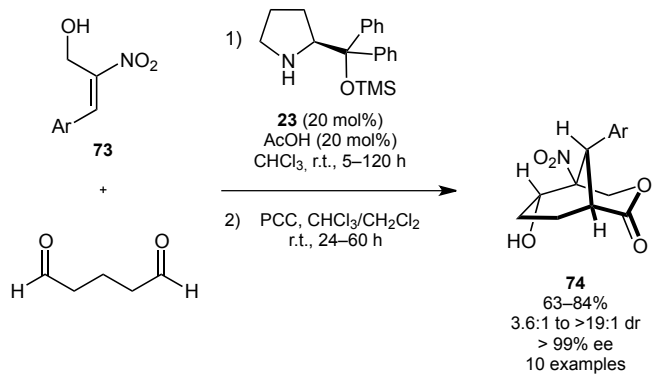
Scheme 34. Enantioselective Michael-Michael-acetalization domino reaction for the access to functionalized bicyclo[3.3.1]nonan-2-ones

In the synthesis of optically active six-membered rings, the group of Hayashi described the first methodology, involving nitroalkenes in a MichaelHenry domino reaction in $2007 .^{31}$ Diphenylsilylprolinol ether $\mathbf{2 3}$ was used to promote the reaction between glutaraldehyde and diverse aromatic and aliphatic nitroolefins (Scheme 35). The enantioenriched cyclohexanols $\mathbf{7 5}$ were formed as one major diastereomer with excellent enantioselectivities and control of four stereogenic centers. More interestingly, other diastereomers could be selectively accessed by treating the carbocycles in acidic (silica) or basic (DBU) conditions, without significant loss of enantioselectivity. Theoretical mechanistic studies and Gibb's free energy calculations were recently carried out by Wong to explain the high stereoselectivity of this Michael-Henry domino reaction. ${ }^{67}$

A recyclable catalytic system to promote the same Michael-Henry transformation was developed in 2011 by $\mathrm{Ni}$ and co-workers with comparable results. ${ }^{68}$ The authors showed that the catalyst could be reused four times without any significant erosion of the rates, yields and stereoselectivities.

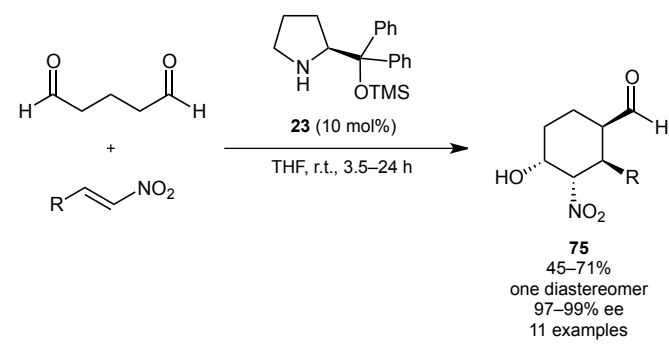

Scheme 35. Domino Michael-Henry reaction for the enantioselective synthesis of cyclohexanols

An interesting extension of the previous work was accomplished by Hong et al. who exploited the reactivity of 2-hydroxynitrostyrene allowing the creation of an additional $\mathrm{C}-\mathrm{O}$ bond in an efficient Michael-acetalization-Henry cascade (Scheme 36) ${ }^{69}$ After subsequent oxidation, this sequence gave high enantiomeric excesses (up to $>99 \%$ ee) and moderate yields and diastereoselectivities in the formation of tetrahydro-6H-benzo $[c]$-chromen-6-ones $\mathbf{7 6}$, which are found in a large range of natural and bioactive molecules.

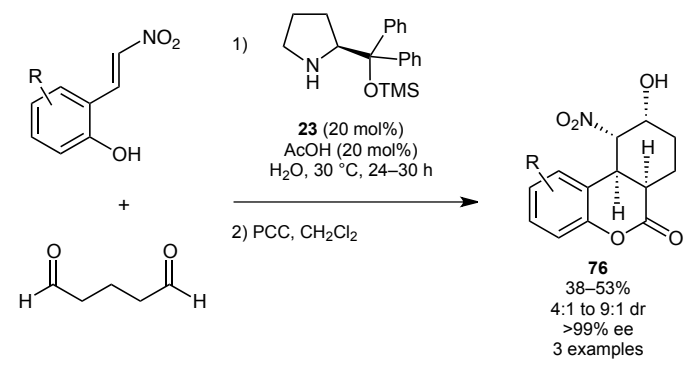

Scheme 36. Henry-Michael-acetalization domino reaction
A Michael-Henry domino transformation between 2substituted 1,3-ketoesters 77 and aromatic nitroolefins was designed by Zhong and co-workers in 2008 (Scheme 37). ${ }^{70}$ A catalytic amount of 9-amino-9deoxy-epi-quinine $\mathbf{7 8}$ was used to generate optically active cyclohexanols $\mathbf{7 9}$ bearing four stereocenters including two quaternary stereogenic centers in excellent yields and stereoselectivities. This methodology constitutes the first efficient MichaelHenry domino reaction using simple ketones as electrophiles.

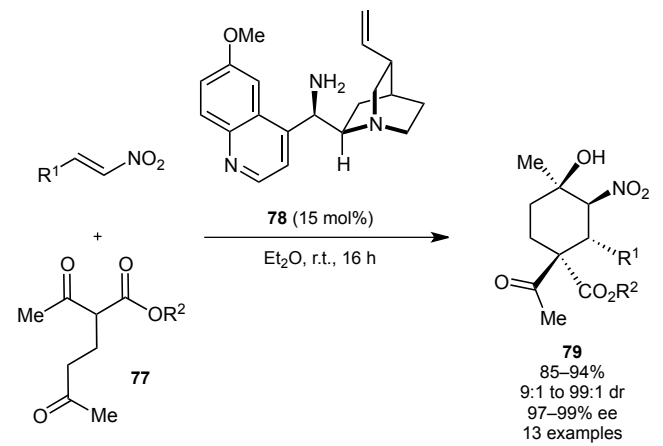

Scheme 37. Michael-Henry domino transformation for the synthesis of tetrasubstituted cyclohexanols

As disclosed by Soós and co-workers in 2011, the configuration of the organocatalyst can play a key role on the outcome of the domino transformation. ${ }^{71}$ They developed a sequential transformation initiated by the Michael addition of nitromethane on chalcones catalyzed by a quinine-derived bifunctional thiourea 42. This catalytic system was then not capable of promoting the subsequent diastereoselective domino Michael-Henry transformation. Using the catalyst's pseudoenantiomer $\mathbf{8 1}$ of $\mathbf{4 2}$ allowed the stereoselective formation of the expected cyclohexanols $\mathbf{8 2}$ bearing five contiguous perfectly controlled stereocenters (Scheme 38), with Michael adducts $\mathbf{8 0}$ as starting material. The previously observed non-reactivity would be due to mismatch effects, kinetically disfavoring the second Michael addition.

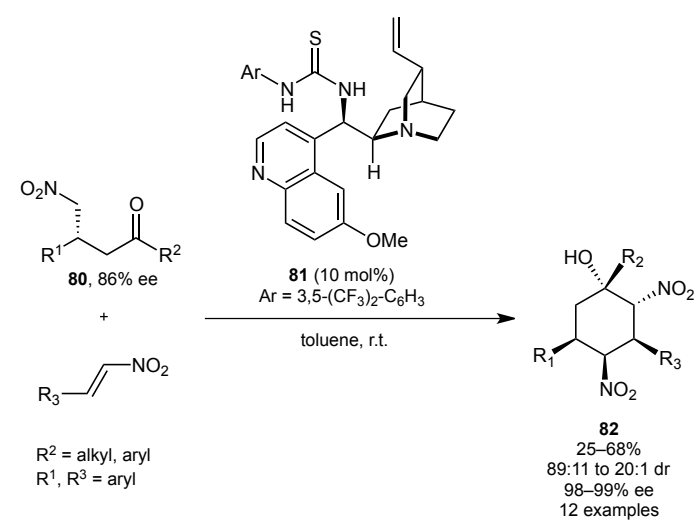

Scheme 38. Michael-Henry domino reaction

Very recently, the group of Alonso described a $O$ methylprolinol 85-catalyzed Michael-aldol cascade between both $\alpha$-nitroenal 84 and 2,2-dimethyl-1,3- 
dioxan-5-one (83) allowing the synthesis of highly oxygenated nitrocyclohexanes $\mathbf{6 9}$ displaying five stereogenic centers with moderate yields and stereoselectivities (Scheme 39). ${ }^{72}$ The authors applied this efficient methodology to the total synthesis of $(+)$ pancratistatin and (-)-tetrodotoxinin natural products.

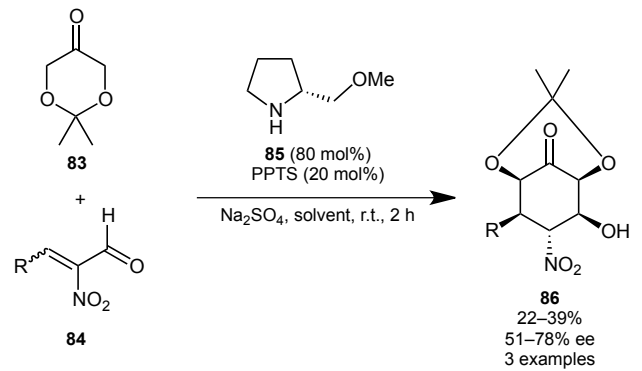

Scheme 39. Access to optically active nitrocyclohexanes by Michael-aldol domino reaction

\subsection{Non Michael-initiated domino reactions}

The first example of non Michael-initiated domino reactions was reported by List and co-workers in 2007 as a triple cascade aldol-dehydration-reduction reaction from simple acyclic 1,5-diketones (Scheme 40). ${ }^{73}$ This domino reaction is catalyzed by a chiral Brønsted acid and accelerated by a "self-sacrificing" achiral primary amine, which is incorporated in the final products 89 . The primary amine is catalyzing the aldol reaction via enamine activation while the terminating reductive amination with Hantzsch ester $\mathbf{8 8}$ is catalyzed by the chiral phosphoric acid 87 affording the cis-3-substituted cyclohexylamines $\mathbf{8 9}$ in good yields and usually excellent stereoselectivities.

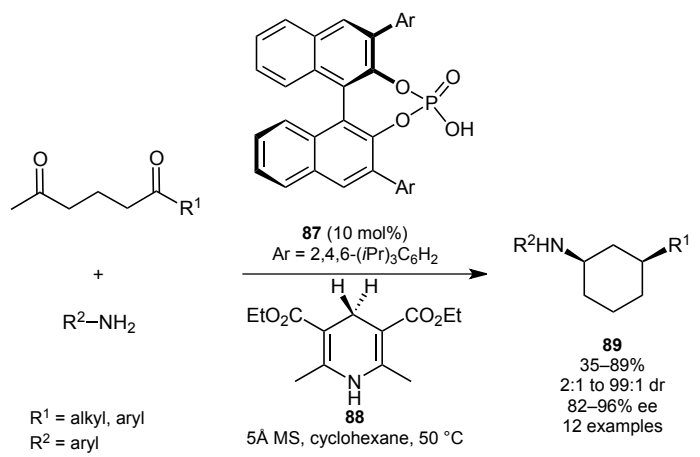

Scheme 40. Aldol-dehydration-reduction cascade reaction for the synthesis of aminocyclohexanes

Very recently, Zhan and co-workers proposed a onepot domino Henry-Michael reaction between nitromethane and 7-oxohept-5-enals 90 (Scheme 41). ${ }^{74}$ Bifunctional thiourea $\mathbf{8 1}$ is catalyzing the domino Henry-Michael reaction providing the desired cyclohexanols 91 with excellent enantioselectivity but poor diastereoselectivity (three diastereomers where obtained). However, addition of an organic base (TMG) promotes a retro-Henry-Henry sequence affording desired products $\mathbf{9 1}$ as single diastereomers.
This stereoconvergent sequence was almost simultaneously reported by Quintavalla et al. who employed a similar bifunctional thiourea organocatalyst/organic base (DBU) system to promote the Henry-Michael-retro-Henry-Henry domino reaction. ${ }^{75}$ They demonstrated the possibility to create an additional stereogenic carbon alpha to the carbonyl moiety in the final cyclohexanol and they applied their methodology to a formal synthesis of $(+)-\gamma$-lycorane.

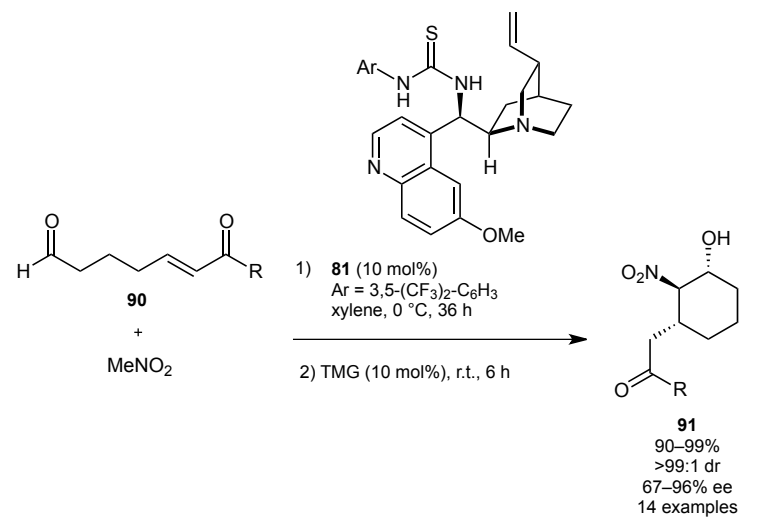

Scheme 41. One pot Henry-Michael-retro-Henry-Henry sequence

Exploiting the innovative organo-SOMO activation (Singly Occupied Molecular Orbital Organocatalysis) developed three years earlier, ${ }^{76}$ MacMillan and coworkers reported a facile access to enantioenriched six-membered rings 93 and 94 in high yields, regioand stereoselectivities (Scheme 42). ${ }^{77}$ They used aldehydes bearing an aryl moiety that could, in the presence of organocatalyst $\mathbf{9 2}$ and an oxidant, generate the radical cation 95, which could then enantioselectively add onto the olefin substrate generating the alkyl radical 96. Oxidation of the latter furnished the cation intermediate 97, which was diastereoselectively trapped by aryl moiety in a final Friedel-Crafts step. A chair like transition state is proposed in order to explain the diastereoselectivity. Notably, the nature of the oxidants counterion $\left(\mathrm{SbF}_{6}{ }^{-}\right)$ is important allowing an improved stabilization of the carbocation intermediate $\mathbf{9 7}$ accounting for a good diastereoselectivity.
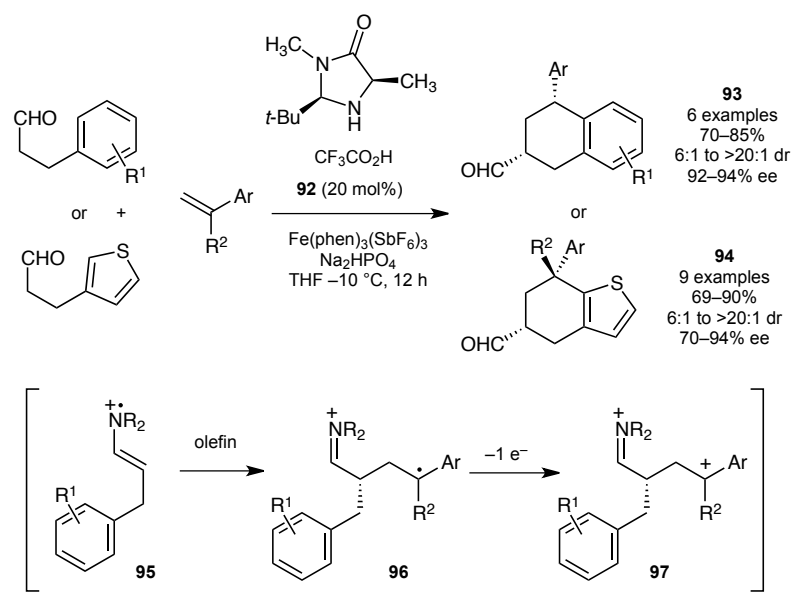
Scheme 42. Enantioselective organo-SOMO cascade for the synthesis of functionalized fused six-membered ring systems

\section{Multicomponent and related transformations}

Multicomponent reactions (MCRs) have emerged over the time as powerful methodologies for the elaboration of complex heterocyclic and carbocyclic structures of both academic and industrial interests. ${ }^{78}$ More recently, the discovery of catalytic asymmetric multicomponent domino reactions (AMCDRs) has provided an important breakthrough in total synthesis of natural products and new synthetic scaffolds bearing multiple stereogenic centers. ${ }^{79}$

The initiator of a recent burgeoning activity in organocatalytic AMCDRs is the pioneer and very elegant Enders' triple organocatalytic cascade reaction reported in 2006 for the enantioselective synthesis of diverse polyfunctional cyclohexene derivatives 98 (Scheme 43). ${ }^{80}$ This three-component reaction involves a linear aldehyde, a nitroalkene, an enal and diphenyl prolinol trimethylsilyl ether $\mathbf{2 3}$ as secondary amine catalyst promoting the Michael-Michaelaldol-dehydration sequence. During this domino cycloalkylation initiated by a Michael addition onto the nitroolefin, four contiguous stereogenic centers are created with good diastereoselectivity and excellent enantioselectivity even when performed in water in the presence of Boc- $D-\alpha$-phenylglycine as additive. ${ }^{81}$

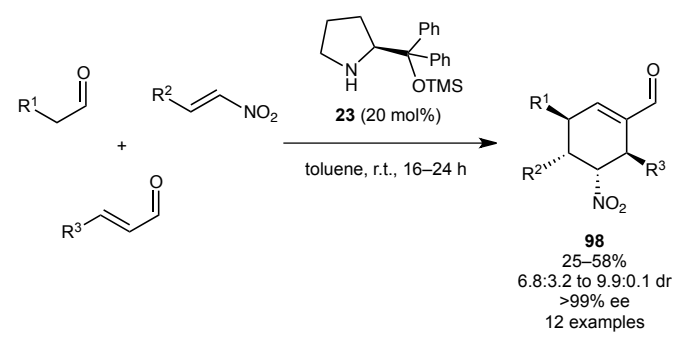

Scheme 43. Domino Michael-Michael-aldol-dehydration for the synthesis of cyclohexenecarboxaldehydes

Clearly, the design and development of new organocatalytic AMCDRs initiated by a Michael addition is an ongoing challenge at the forefront of synthetic organic chemistry. Variations of the functionalities on the starting substrates, combined with different modes of activation, has promoted the outbreak of many recent innovative cascades. In the following sections, we will present the diverse contributions based on the nature of the Michael acceptor involved either in a pseudo-multicomponent reaction, a consecutive reaction or a multicomponent reaction. ${ }^{82}$

\subsection{Pseudo three-component reactions}

A pseudo three-component reaction is a domino sequence, in which one equivalent of the substrate is used in combination with at least two equivalents of the second partner. Both partners are introduced in the reaction media since the beginning of the sequence. This strategy has been efficiently applied to the asymmetric synthesis of cyclohexanes or cyclohexenes, as illustrated in the following examples.

\subsubsection{Michael-initiated domino reactions with nitroolefins}

After the pioneering results from Enders' group concerning the control of four stereogenic centers in the synthesis of cyclohexenes, ${ }^{80}$ we reported in 2010 the first example of an organocatalyzed cascade allowing the direct access to a hexasubstituted cyclohexane skeleton with control of all six stereocenters. ${ }^{83}$ Thus, the reaction between $\alpha$ ketoamide 99 and two equivalents of nitroolefin in the presence of the Takemoto catalyst $\mathbf{6 1}$ afforded after four days at room temperature, the hexasubstituted cyclohexane 100, that was isolated in good yield as a unique enantiomerically pure diastereomer among the 64 possible stereoisomers. This pseudo threecomponent sequence based on a Michael-MichaelHenry type of cascade reaction resulted in the formation of three new $\mathrm{C}-\mathrm{C}$ bonds and the totally stereocontrolled formation of six contiguous stereogenic centers.

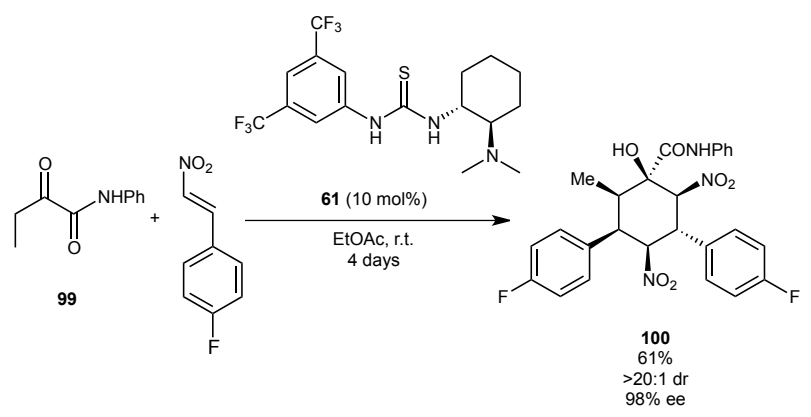

Scheme 44. Enantioselective synthesis of hexasubstituted cyclohexane

More recently, the group of Wang developed a highly diastereo- and enantioselective access to hexasubstituted cyclohexanols $\mathbf{1 0 1}$ from two simple partners, i.e. one equivalent of an aliphatic aldehyde and two equivalents of a nitroolefin, using a strategy based on the one-pot combination of two different organocatalysts (Scheme 45). ${ }^{84}$ The cascade first involves the Michael addition of the aldehyde to the nitroolefin via enamine activation by the chiral secondary amine catalyst $\mathbf{2 3}$. The bifunctional thiourea-tertiary amine catalyst $\mathbf{4 2}$ then successively promotes a Michael addition of the adduct to a second equivalent of the nitroolefin, and the final intramolecular aldol reaction. 


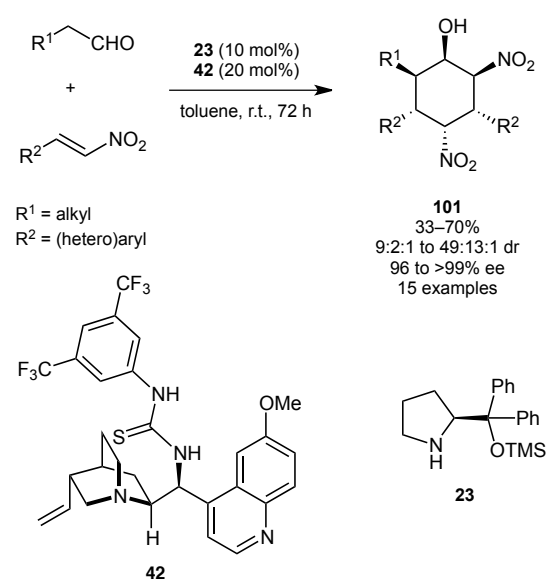

Scheme 45. Diastereo- and enantioselective synthesis of hexasubstituted cyclohexanols using a combination of two different organocatalysts

With the aim of developing biologically inspired multicomponent cascades, Rueping and co-workers developed an enantioselective access to pentasubstituted cyclohexenes $\mathbf{1 0 2}$ from a 2:1 mixture of simple enals and nitroolefins (Scheme 46). ${ }^{85}$ They demonstrated that it was possible to chemoselectively convert an enal into the corresponding saturated aldehyde in the presence of a nitroolefin, through TMS-protected diphenylprolinol 23-catalyzed transfer hydrogenation from Hantzsch dihydropyridine $\mathbf{8 8}$. Thus, they cunningly transformed a pseudo threecomponent reaction into a real three-component domino sequence, one of the two equivalents of the enal being in situ converted into an aldehyde which could stereoselectively add to the nitroalkene through enamine activation. Consequently, cyclohexenes $\mathbf{1 0 2}$ containing four adjacent chiral centers could be obtained as a single diastereomer in moderate to good yields and excellent enantioselectivities, through a hydrogenation-Michael-Michael-aldol quadruple domino sequence involving three different partners, i.e. an aliphatic aldehyde, an enal and a nitroolefin.

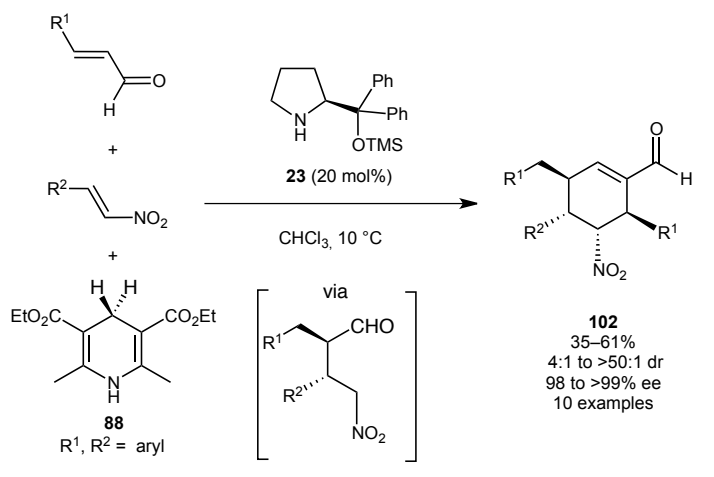

Scheme 46. Quadruple domino reaction strategy for the enantioselective synthesis of tetrasubstituted cyclohexenes

Very recently, the group of Enders introduced the new concept of branched domino reaction, which they applied to a pseudo three-component four-step asymmetric synthesis of pentasubstituted cyclohexenes 103 containing four adjacent stereogenic centers. ${ }^{86}$ Their strategy is based on the possible generation of both a Michael donor and a Michael acceptor from the same aldehyde, i.e. enamine activation of the aldehyde with secondary amine catalyst $\mathbf{3 1}$ on the one hand, and parallel oxidation of this enamine intermediate with IBX to the corresponding conjugated iminium on the other hand. Thus, starting from only two simple partners, they were able to design a chiral secondary aminecatalyzed enamine oxidation-Michael-Michael-aldol sequence affording polyfunctionalized cyclohexenes 103 with good to excellent diasteroselectivities and excellent enantioselectivities (Scheme 47). Moreover, their methodology revealed particularly relevant when nitroolefins were replaced by alkylidene oxindole derivatives as acceptors, leading to enantiomerically pure oxindole-derived spiro compounds.

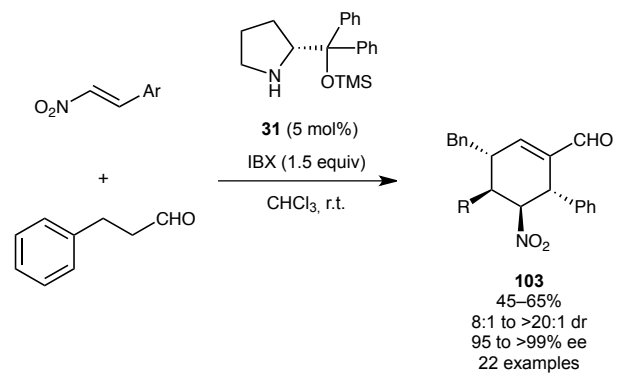

Scheme 47. Branched domino reaction for the enantioselective synthesis of polysubstituted cyclohexenes

\subsubsection{Michael-initiated domino reactions with $\alpha, \beta$ - unsaturated carbonyl compounds}

In 2007, Jørgensen and co-workers described a powerful enantioselective access to cyclohexene carboxaldehydes 104 by reaction of malononitrile with two equivalents of an $\alpha, \beta$-unsaturated aldehyde, in the presence of diarylsilylprolinol catalyst $\mathbf{1 0}$ (Scheme 48). ${ }^{87}$ The reaction proceeded in good to high yields and products were isolated in almost diastereomerically and enantiomerically pure form. The methodology, that proceeded by iminiumiminium-enamine successive activation of the unsaturated carbonyl compound was successfully extended to cyanoacetates, with only a slight erosion of the diastereocontrol. Similar excellent results starting from nitromethane and enals were later reported by the group of Enders. ${ }^{88}$

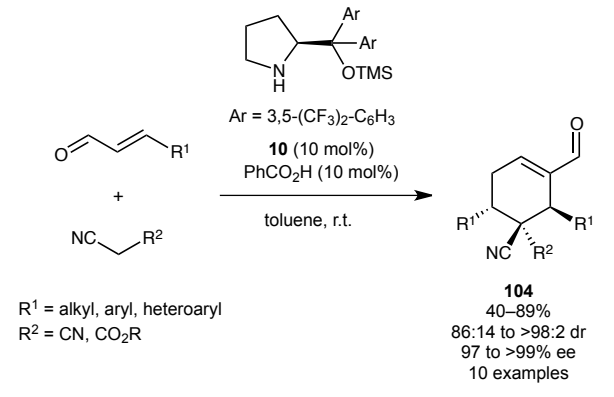

Scheme 48. Michael-Michael-aldol sequence for the enantioselective synthesis of cyclohexenes 
In 2010, Rios and co-workers demonstrated that when heterocycles such as oxindoles, benzofuranones, pyrazolones or azalactones were introduced as pronucleophiles in similar sequences, spiro compounds 105 were accessible in high yields and, in most of the cases high stereocontrol (Scheme 49). ${ }^{89}$ Reactions of oxindoles with aromatic enals afforded the desired products with excellent diastereo- and enantioselectivities, whereas aliphatic enals gave lower diastereoselectivities. It is noteworthy that the use of benzoic acid is crucial in this sequence, probably to promote the irreversible dehydration last step, thus preventing undesired retro-Michael reactions. This methodology was particularly suitable for the highly stereoselective synthesis of spiropyrazolones. Interestingly enough, significant positive nonlinear effects were observed in this case. ${ }^{90}$ The use of benzofuranone as bis-nucleophile in a pseudo three-component reaction was also reported by the group of Melchiorre, who obtained similar enantiomerically enriched spirocyclic benzofuranones. ${ }^{50}$

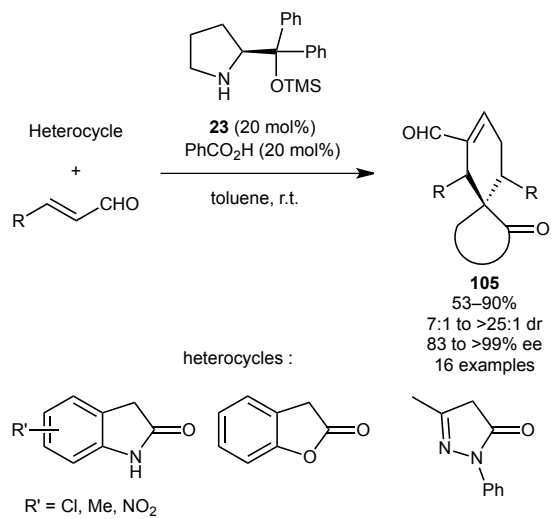

Scheme 49. Organocatalyzed Michael-Michael-aldol sequence for the stereoselective synthesis of spiro compounds

As an efficient synthetic application of one of the rare enantioselective $\mathrm{N}$-alkylations of indole derivatives, Enders et al. recently described a highly stereoselective access to tetracyclic indole structures 107 containing six stereocenters through a quadruple domino sequence from $\alpha, \beta$-unsaturated aromatic aldehydes and indole-2-methylene malononitrile derivatives 106 (Scheme 50). ${ }^{91}$ This pseudo threecomponent strategy involves an aza-MichaelMichael-Michael-aldol cascade, resulting in the formation of four new $\mathrm{C}-\mathrm{C}$ bonds, one $\mathrm{C}-\mathrm{N}$ bond and six stereogenic centers with high diastereo- and enantioselectivities. The resulting products were finally engaged in a Wittig reaction.

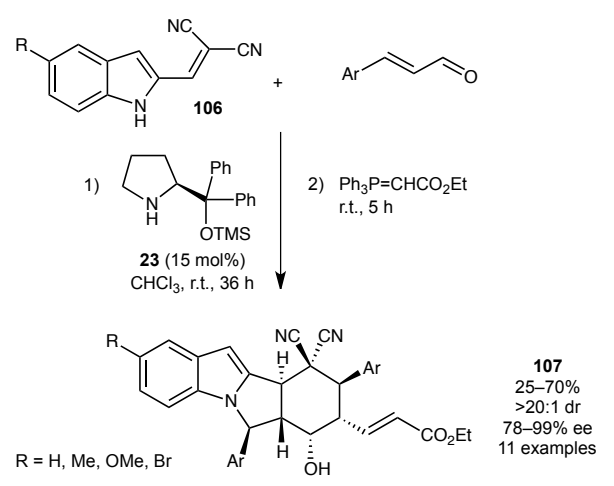

Scheme 50. Quadruple domino pseudo three-component sequence leading to tetracyclic indole derivatives

The group of Jørgensen also developed a pseudo three-component reaction based on a one-pot two-step Michael-aldol-Michael-aldol sequence in which the donor was used in excess with respect to the aldehyde. In this context, they described a co-catalytic system composed of a chiral secondary amine $\mathbf{2 3}$ and piperidine for the highly stereoselective access to bicyclo[3.3.1]non-2-ene derivatives $\mathbf{1 0 8}$ from two equivalents of dimethyl 3-oxopentanedioate (7) and conjugated enals (Scheme 51). ${ }^{92}$ Only one out of sixty four stereoisomers of the bicyclic product bearing six stereogenic centers was formed from these simple acyclic and achiral substrates.

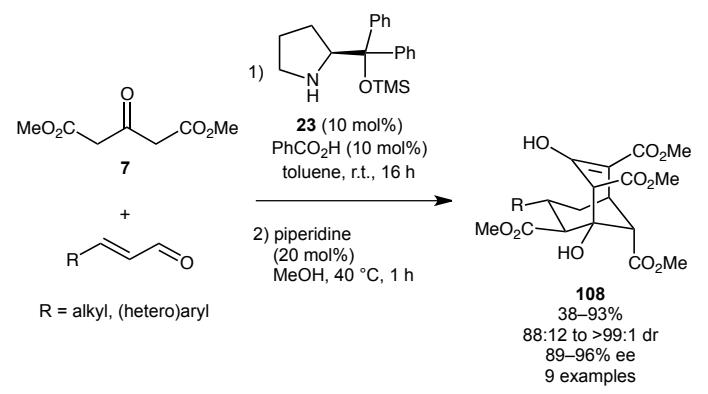

Scheme 51. Organocatalyzed asymmetric pseudo threecomponent access to bicyclo[3.3.1]non-2-enes

\subsection{Consecutive reactions}

From a general point of view, when more than two different partners are involved at the same time in one reaction, the strategy may be labeled as a multicomponent approach. However, when more than two reactants are sequentially introduced in the reaction media or an operationally simple change of the experimental conditions is needed, the term consecutive reaction is more appropriated. ${ }^{82}$ Based on these considerations, several consecutive reactions have been designed for the asymmetric synthesis of polysubstituted cyclohexanes.

\subsubsection{Michael-initiated domino reactions with nitroolefins}

To date, the only example of such a transformation is due to Enders et al., who recently described a highly 
diastereo- and enantioselective one-pot consecutive three-component sequence for the synthesis of hexasubstituted cyclohexanols 110 (Scheme 52). ${ }^{93}$ The initial step is a bifunctional thiourea amine 109catalyzed asymmetric Michael addition of a $\beta$ ketoester to a nitroolefin. After $24 \mathrm{~h}$ at room temperature, an enal and an achiral secondary amine are then added in stoichiometric amounts, resulting in a diastereoselective domino Michael-aldol sequence yielding the desired products. The general scope of this sequence generated a large family of cyclohexanols 110 bearing diverse functional groups such as hydroxy, ester or nitro on the same skeleton. During this highly regio- and stereoselective process, up to three new $\mathrm{C}-\mathrm{C}$ bonds and six adjacent stereogenic centers including a quaternary one are created.

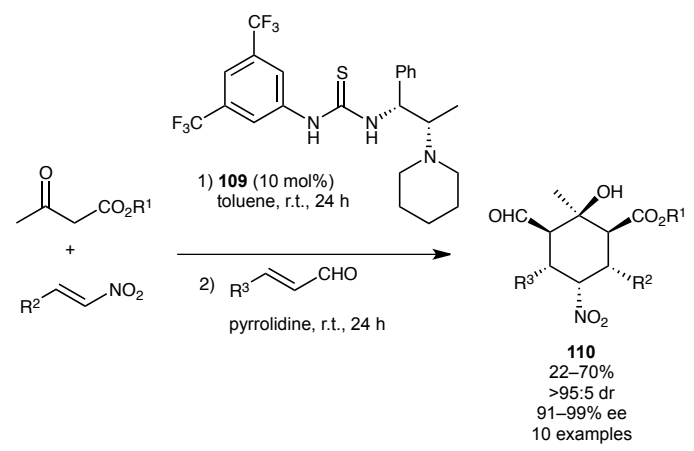

Scheme 52. Asymmetric synthesis of cyclohexanols via an organocatalyzed consecutive Michael-Michael-aldol sequence

\subsubsection{Michael-initiated domino reactions with $\alpha, \beta$-unsaturated carbonyl compounds}

In 2009, the group of Alemán described an interesting consecutive Michael-double Henry reaction for the synthesis of tetrasubstituted cyclohexanols from enals, 1,3-diketones and nitromethane (Scheme 53). ${ }^{94}$ The first step consisted in a highly enantioselective Michael addition promoted by the Hayashi-Jørgensen catalyst 10. Then, addition of nitromethane in the presence of a catalytic amount of tetrabutylammonium fluoride (TBAF) acting as a weak base resulted in two consecutive intermolecular and intramolecular Henry reactions. The corresponding cyclohexanols 111 were obtained with a total stereocontrol of all five stereogenic centers.

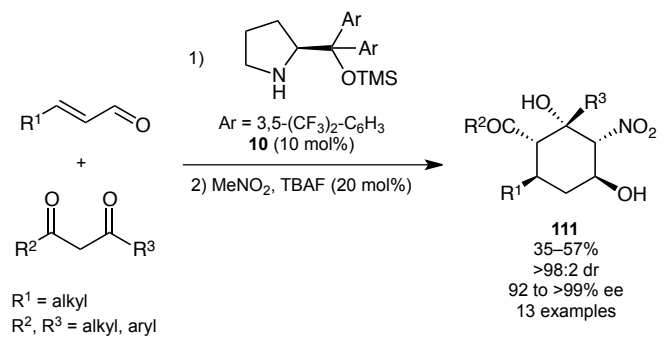

Scheme 53. Asymmetric synthesis of tetrasubstituted cyclohexanols
More recently, Hong et al. described a highly enantioselective organocatalyzed three-component consecutive reaction for the synthesis of isochromene pyrimidinedione fused to a six-membered ring 113 (Scheme 54). ${ }^{95}$ The overall one-pot three-steps sequence consisted in a preliminary asymmetric Michael addition of an olefinic nitroalkane $\mathbf{1 1 2}$ to an enal via iminium activation of the acceptor, which allowed the enantiocontrol of two adjacent chiral centers. The consecutive addition of 1,3dimethylbarbituric acid resulted in a Knoevenagelhetero Diels-Alder cascade reaction leading to the tricyclic product in a $1: 1$ ratio of diastereomers. Finally, isomerization in the presence of 1,8diazabicyclo[5.4.0] undec-7-ene (DBU) afforded the only observable isomer with high enantiomeric excess.

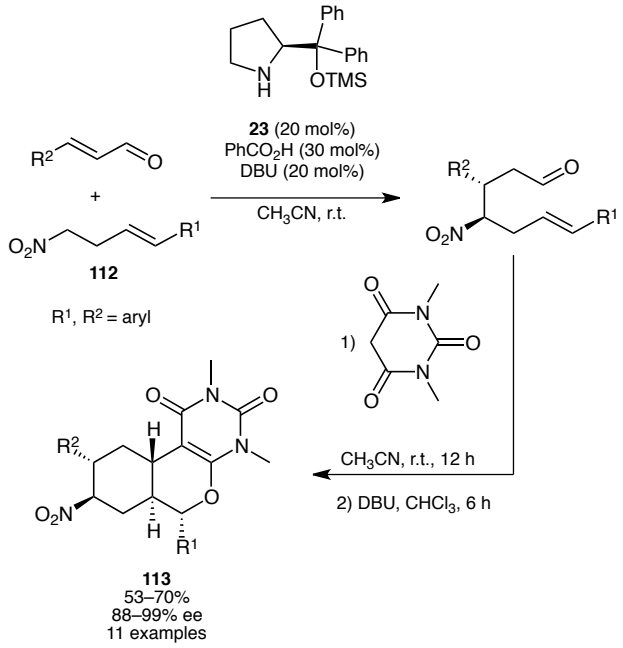

Scheme 54. Organocatalyzed Michael-Knoevenagel-HeteroDiels-Alder sequence

\subsection{Multicomponent reactions}

\subsubsection{Michael-initiated domino reactions with nitroolefins}

Shortly after their original triple organocatalytic cascade, ${ }^{80}$ Enders and collaborators have design a new one-pot procedure to construct polyfunctionalized tricyclic carbon frameworks 114 and 115 of the hainanolide and amphilectane families bearing up to eight stereogenic centers (Scheme 55) ${ }^{96}$ The aliphatic aldehyde donor bears a butadienyl side chain which is engaged in a final intramolecular Diels-Alder cycloaddition to the conjugated double bond of the cyclohexene carboxaldehyde intermediate generated by the domino Michael-Michael-aldol-dehydration sequence. 

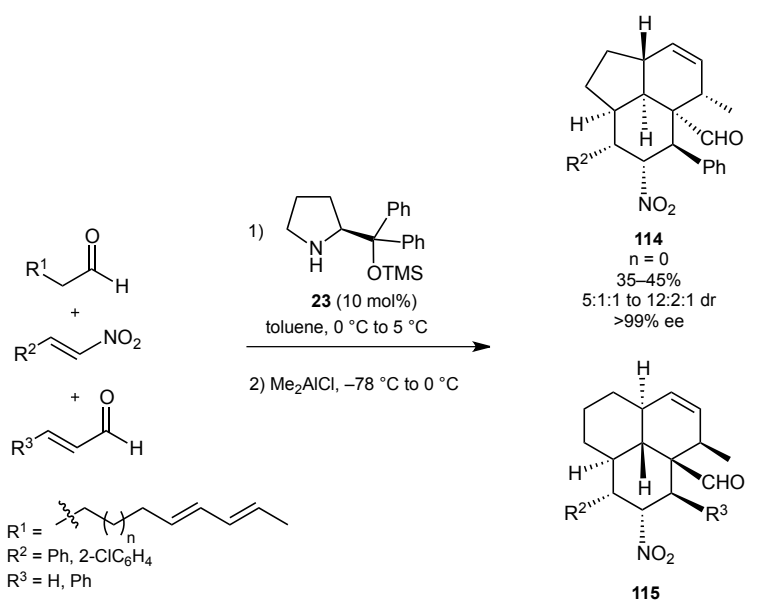

$>99 \%$

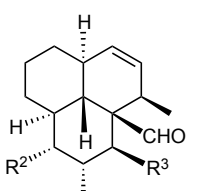

ํㅡㄹ

115
$n=1$

115
$n=1$
$49-56 \%$

$49-56 \%$
$0: 1$ to $15: 1 \mathrm{dr}$

$>99 \%$ ee

Scheme 55. One-pot triple organocatalytic cascade-DielsAlder sequence

More recently, the same group has extended the scope of this powerful three-component reaction for the synthesis of thiadecalins $\mathbf{1 1 7}$ and in a sequential five or two steps fashion, respectively, starting from $\omega$ functionalized linear aldehydes 116 (Scheme 56). ${ }^{97}$

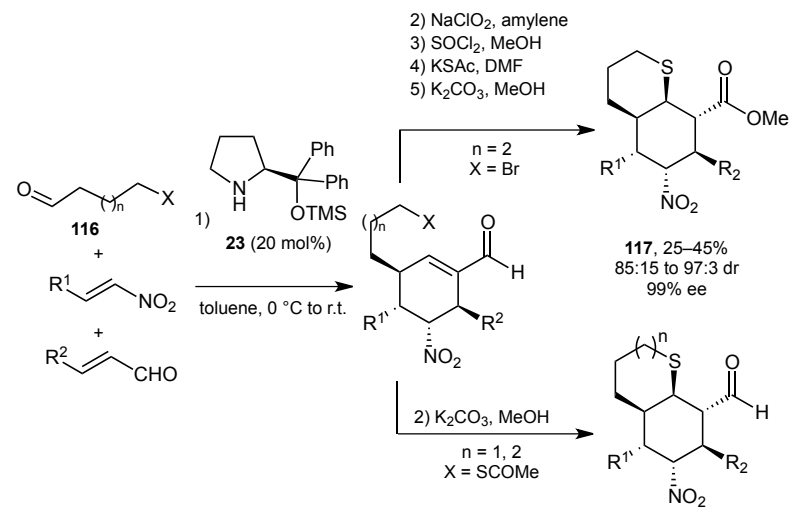

Scheme 56. Asymmetric sequential synthesis of thiadecalins

A complementary quadruple cascade initiated by a Friedel-Crafts-type reaction with electron-rich arenes has been also very recently introduced by Enders' group. ${ }^{98}$ The overall four-component reaction involves up to three different Michael acceptors and gives rise to highly functionalized and valuable cyclohexanecarbaldehydes $\mathbf{1 1 8}$ bearing an aniline moiety (Scheme 57). Additionally, benzylidene malononitriles can be used instead of the nitroalkene partner in this domino transformation. Here also, diphenylprolinol trimethylsilyl ether $\mathbf{2 3}$ is the catalyst of choice allowing the control of up to four stereogenic centers with very good diastereo- and excellent enantioselectivity.

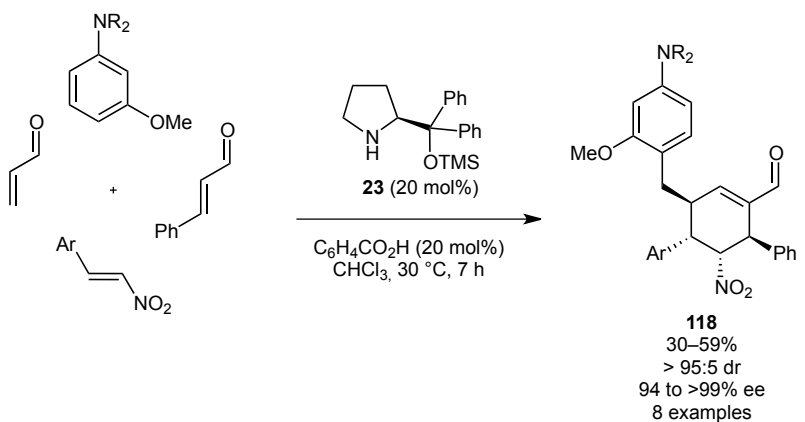

Scheme 57. Quadruple cascade initiated by a Friedel-Craftstype reaction

An asymmetric organocatalytic relay cascade (AORC) involving malonates as nucleophiles has been proposed by the groups of $\mathrm{Xu}$ and Dixon in 2009 leading to cyclohexanols $\mathbf{1 2 0}$ with four stereogenic centers in good yields, moderate diastereoselectivities and excellent enantioselectivities (Scheme 58). ${ }^{99}$ Their strategy is based on the utilization of two compatible orthogonal catalysts acting mutually via two different activation modes. The best catalytic combination was found to be the activation of the malonate by a bifunctional thiourea-cinchona catalyst $\mathbf{4 2}$, promoting the first Michael addition onto the nitrololefin, with diphenyl prolinol triethylsilyl ether $\mathbf{1 1 9}$ for the iminium activation of the $\alpha, \beta$-unsaturated aldehyde. A recent extension of this synthetic strategy involving the combination of two different organocatalysts was proposed in the case of $N$-substituted oxindoles as pronucleophiles instead of a malonate leading to sixmembered spirocyclic oxindoles. ${ }^{100}$

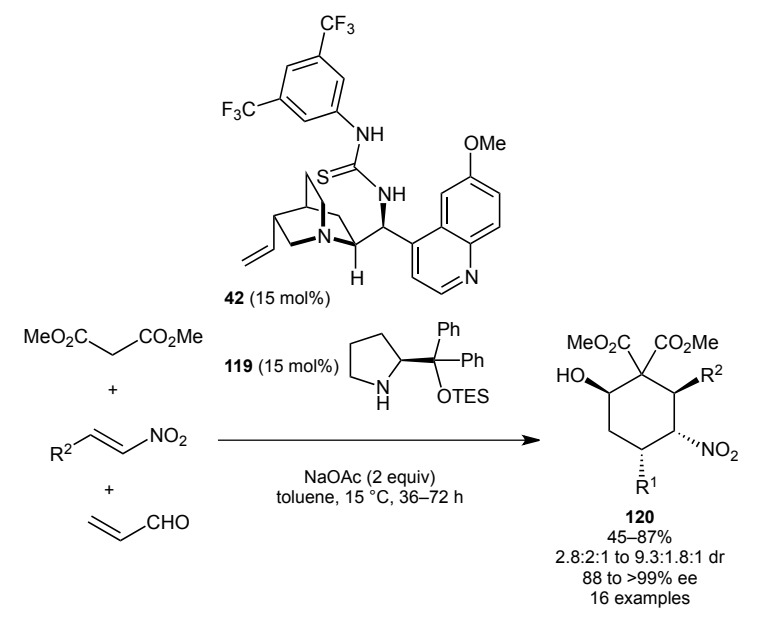

Scheme 58. Asymmetric organocatalytic relay cascade (AORC) for the synthesis of cyclohexanols

\subsubsection{Michael-initiated domino reactions with $\alpha, \beta-$ unsaturated carbonyl compounds}

The 1,4-addition of carbon-centered nucleophiles to $\alpha, \beta$-unsaturated compounds is the archetype of the Michael addition, ${ }^{101}$ which has found many recent developments in its organocatalytic version. ${ }^{16}$ Of special interest are conjugated aldehydes that can be easily activated as chiral iminiums by secondary 
amine organocatalysts ${ }^{102}$ and involved in domino sequences.

An interesting example was proposed by Melchiorre's group in 2009, with a triple organocascade for the one-pot construction of six-membered spirocyclic $N$ $\mathrm{H}$ oxindoles 121 (Scheme 59). ${ }^{49}$ Aliphatic aldehydes were used as nucleophiles in combination with electron-deficient olefinic oxindoles and $\alpha, \beta$ unsaturated aldehydes as electropliles in a enamineiminium-enamine cascade catalyzed by diphenyl prolinol trimethylsilyl ether $\mathbf{2 3}$ in the presence of $o$ fluorobenzoic acid and followed by an in situ dehydration step. Short after this study, Chen and collaborators proposed a closely related formal $[2+2+2]$ annulation strategy with $N$-Boc protected oxindoles involving a dehydration step promoted by trifluoracetic acid (TFA). ${ }^{103}$

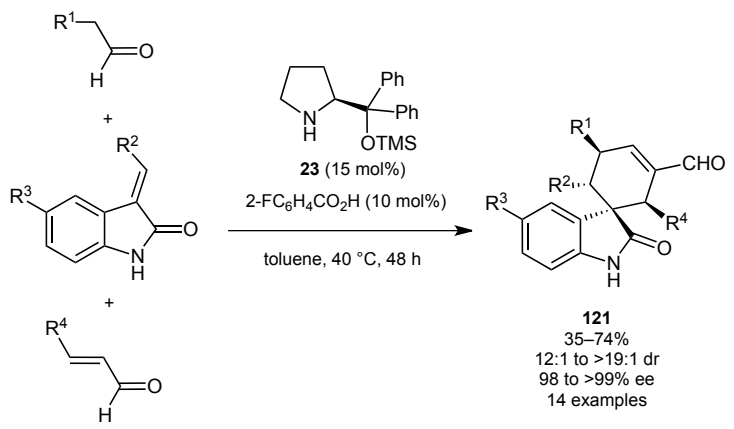

Scheme 59. Triple organocascade for the one-pot construction of six-membered spirocyclic $\mathrm{N}-\mathrm{H}$ oxindoles

This efficient annulation strategy was extrapolated one year latter independently by the groups of Melchiorre $^{50}$ and Rios ${ }^{104}$ to olefinic benzofuranones and pyrazolones as electrophiles, respectively. This allowed a straightforward access to spirobenzofuranone $\mathbf{1 2 2}$ and spiropyrazolone cyclohexene carboxaldehydes 123 with good yields and excellent stereocontrol (Scheme 60).

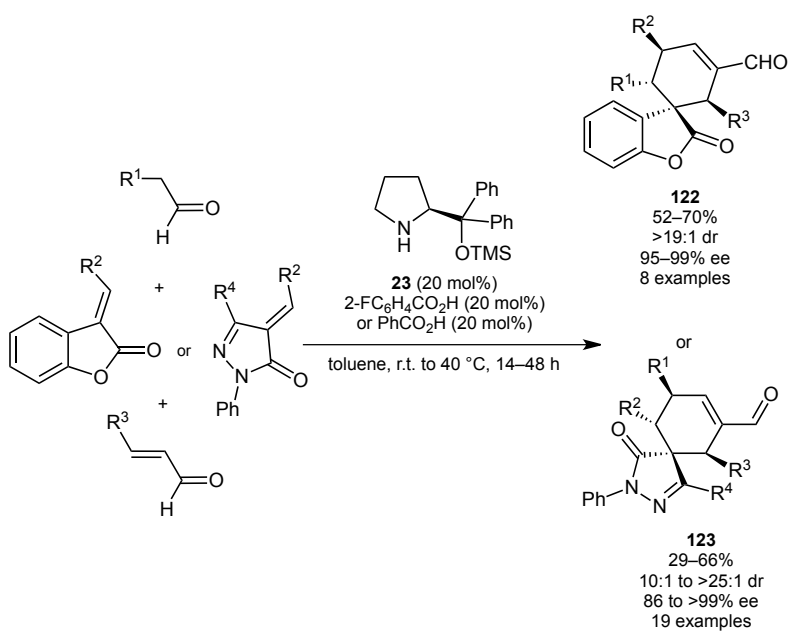

Scheme 60. Triple enamine-iminiums-enamine cascade for the synthesis of spirobenzofuranone and spiropyrazolone cyclohexene carboxaldehydes

Alternatively, for the construction of complex spirooxindoles, Chen's group proposed a complementary approach involving functionalized oxobutenoate oxindoles $\mathbf{1 2 4}$ as nucleophiles combined with two different $\alpha, \beta$-unsaturated aldehydes as electrophiles (Scheme 61). ${ }^{103 b}$ In this case, the corresponding quadruple domino sequence leads directly to the expected spiro tricyclic structures $\mathbf{1 2 5}$ bearing six stereogenic centers and a fused hydroindane motif.

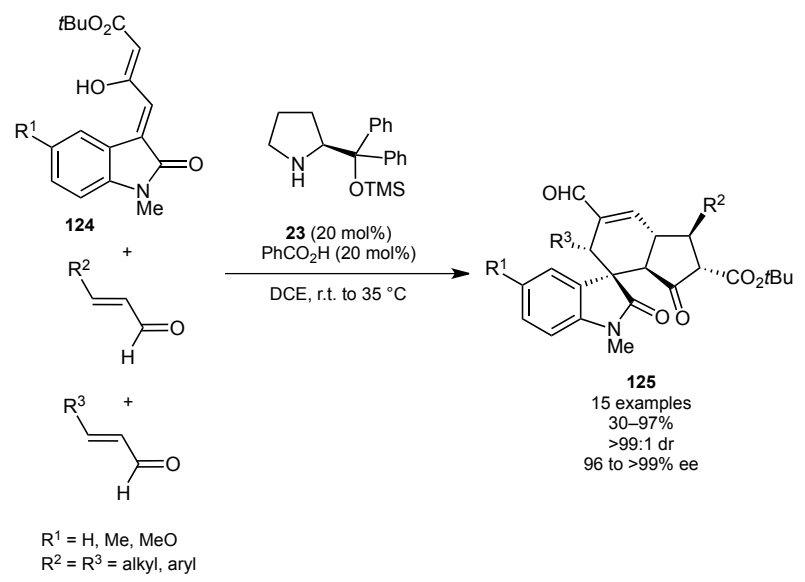

Scheme 61. Quadruple domino cascade for the synthesis of spirotricyclic oxindoles

Hetero-Michael additions are also particularly attractive and more particularly, oxa-Michael addition $^{105}$ has been proposed to initiate powerful domino sequences with concomitant formation of sixmembered carbocycles. Hong's group ${ }^{106}$ reported an elegant three-component quadruple domino reaction from 2-hydroxynitrostyrene and two different enals to produce stereodefined optically active tetrahydro- $6 \mathrm{H}$ benzo[c]chromenes $\mathbf{1 2 6}$ through iminium-enamineiminium-enamine activation sequence catalyzed by diphenyl prolinol trimethylsilyl ether $\mathbf{2 3}$ (Scheme 62). The complete organocascade follows a domino oxaMichael-Michael-Michael-aldol-dehydration sequence, and was exploited for the total synthesis of the natural product $(+)$-conicol. ${ }^{106 \mathrm{~b}}$

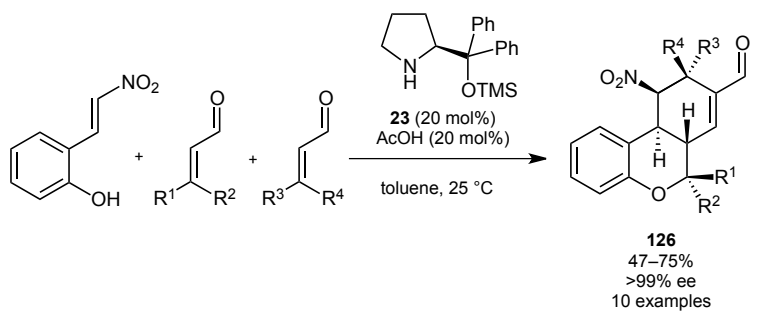

Scheme 62. Three-component quadruple domino iminiumenamine-iminium-enamine cascade

Simultaneously, Gong and co-workers, ${ }^{107}$ have elaborated a related pseudo four-component quadruple domino reaction with simple alcohols as initiators of the oxa-Michael addition onto acrolein (Scheme 63). In the presence of a nitroolefin, the overall oxaMichael-Michael-Michael-aldol-dehydration sequence catalyzed by TMS-protected diphenyl 
prolinol 23 afforded functionalized cyclohexene carboxaldehydes 127 with excellent stereoselectivity and good chemical yields.

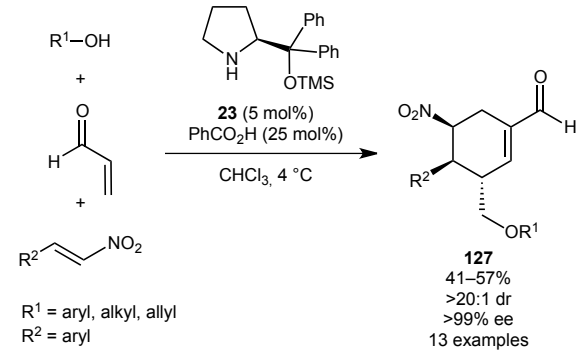

Scheme 63. Quadruple oxa-Michael-Michael-Michael-aldol sequence for the synthesis of functionalized cyclohexene carboxaldehydes.

\section{Conclusion}

From this review, one can notice that the advent of organocatalysis in the beginning of the century has without a doubt contributed to the rapid increase of efficient domino methodologies for the formation of six-membered carbocycles. Two-component as well as multicomponent organocatalyzed approaches allow the construction of polysubstituted cyclohexanes and cyclohexenes with concomitant creation and control of several stereogenic carbon atoms (up to six). Even if the enamine-iminium activation mode is the most exploited (in almost $80 \%$ of the time), hydrogenbonding catalysis is also capable of promoting such transformations. We can envision that other (such as nucleophilic catalysis) or more complex combination of several activation modes will be used in the near future to further increase the molecular complexity of the final carbocyclic architectures.

\section{Acknowledgment}

Financial support from Centre National de la Recherche Scientifique (CNRS) and the Aix-Marseille Université are gratefully acknowledged. The authors are very grateful to Professor D. Enders for his invitation to write this review.

\section{References}

(1) Couper, A. S. Annal. Chim. Phys. 1858, 53, 469.

(2) Kekulé, A. Ann. Chem. Pharm. 1858, 106, 129.

(3) Li, J. J. (ed) (2010) Six-Membered Carbocycles, in Name Reactions for Carbocyclic Ring Formations, John Wiley \& Sons, Inc., Hoboken, NJ, USA.

(4) (a) Baeyer, A. Ann. 1894, 278, 111. (b) Warnhoff, E. W. J. Chem. Educ. 1996, 73, 494.

(5) Diels, O.; Alder, K. Ann. 1928, 460, 98.

(6) Rapson, W. S.; Robinson, R. J. Chem. Soc. 1935, 1285.

(7) Schutlz, A. G. Acc. Chem. Res. 1990, 23, 207.

(8) For a review on organocatalytic Diels-Alder reactions, see: Merino, P.; Marqués-López, E.; Tejero, T.; Herrera, R. P. Synthesis 2010, 1.
(9) Eder, U. ; Sauer, G. ; Wiechert, R. Angew. Chem. Int. Ed. 1971, 10, 496.

(10) Hajos, Z. G. ; Parrish, D. R. J. Org. Chem. 1974, 39, 1615.

(11) Bui, T.; Barbas III, C. F. Tetrahedron Lett. 2000, 41, 6951.

(12) (a) Ramachary, D. B.; Chowdari, N. S.; Barbas III, C. F. Angew. Chem. Int. Ed. 2003, 42, 4233. (b) Ramachary, D. B.; Anebouselvy, K.; Chowdari, N. S.; Barbas III, C. F. J. Org. Chem. 2004, 69, 5838.

(13) For the pioneer development of this strategy in the racemic series and synthetic applications, see: (a) Tietze, L. F.; Rackelmann, N.; Müller, I. Chem. Eur. J. 2004, 10, 2722. (b) Sabitha, G.; Fatima, N.; Reddy, E. V.; Yadav, J. S. Adv. Synth. Catal. 2005, 347, 1353. (c) Khoshkholgh, M. J.; Balalaie, S.; Bijanzadeh, H. R.; Rominiger, F.; Gross, J. H. Tetrahedron Lett. 2008, 49, 6965.

(14) For general reviews on organocascade reactions, see: (a) Pellissier, H. Adv. Synth. Catal. 2012, 354, 237. (b) Moyano, A.; Rios, R. Chem. Rev. 2011, 111, 4703. (c) Grondal, C.; Jeanty, M.; Enders, D. Nat. Chem. 2010, 2, 167. (d) Alba, A.-N.; Companyó, X.; Viciano, M.; Rios, R. Curr. Org. Chem. 2009, 13, 1432. (e) Enders, D.; Grondal, C.; Hüttl, M. R. M. Angew. Chem., Int. Ed. 2007, 46, 1570 .

(15) Bonne. D.; Constantieux, T.; Coquerel, Y.; Rodriguez, J. Chem. Eur. J. 2013, 19, 2218.

(16) Tsogoeva, S. B. Eur. J. Org. Chem. 2007, 1701.

(17) (a) Yamaguchi, M.; Yokota, N.; Minami, T. J. Chem. Soc., Chem. Commun. 1991, 1088. (b) Yamaguchi, M.; Shiraishi, T.; Hirama, M. Angew. Chem., Int. Ed. Engl. 1993, 32, 1176. (c) Yamaguchi, M.; Shiraishi, T.; Hirama, M. J. Org. Chem. 1996, 61, 3520.

(18) Halland, N.; Aburel, P. S.; Jørgensen, K. A. Angew. Chem., Int. Ed. 2003, 42, 661.

(19) Berner, O. M.; Tedeschi, L.; Enders, D. Eur. J. Org. Chem. 2002, 1877.

(20) (a) List, B.; Pojarliev, P.; Martin, H. J. Org. Lett. 2001, 3, 2423. (b) List, B. Acc. Chem. Res. 2004, 37, 548.

(21) Halland, N.; Aburel, S. P; Jørgensen, K. A. Angew. Chem. Int. Ed. 2004, 43, 1272.

(22) Pulkkinen, J.; Aburel, P. S.; Halland, N.; Jørgensen, K. A. Adv. Synth. Cat. 2004, 346, 1077.

(23) Hayashi, T.; Toyoshima, M.; Gotoh, H.; Ishikawa, H. Org. Lett. 2009, 11, 45.

(24) Carlone, A.; Marigo, M.; North, C.; Landa, A.; Jørgensen, K. A. Chem. Comm. 2006, 4928.

(25) Yang, Y.-Q.; Chai, Z.; Wang, H.-F.; Chen, X.-K.; Cui, H.-F.; Zheng, C.-W.; Xiao, H.; Li, P.; Zhao, G. Chem. Eur. J. 2009, 15, 13295.

(26) Marigo, M.; Bertelsen, B.; Landa, A.; Jørgensen, K. A. J. Am. Chem. Soc. 2006, 128, 5475.

(27) Cao, C.-L.; Sun, X.-L.; Kang, Y.-B; Tang, Y. Org. Lett. 2007, 9, 4151. 
(28) Wang, X.-J.; Zhao, Y.; Liu, J.-T. Synthesis 2008, 3967.

(29) Yang, H.; Carter, R. G. Org. Lett. 2010, 12, 3108.

(30) Inokoishi, Y.; Sasakura, N.; Nakano, K.; Ichikawa, Y.; Kotsuki, H. Org. Lett. 2010, 12, 1616.

(31) Hayashi, Y.; Okano, T.; Aratake, S.; Hazelard, D. Angew. Chem. Int. Ed. 2007, 46, 4922.

(32) Enders, D.; Narine, A. A.; Benninghaus, T. R.; Raabe, G. Synlett 2007, 1667.

(33) Enders, D.; Wang, C.; Bats, J. W. Synlett 2009, 1777.

(34) Anwar, S.; Chang, H.-J.; Chen, K. Org. Lett. 2011, 13, 2200 .

(35) Reyes, E.; Jiang, H.; Milelli, A.; Elsner, P.; Hazell, R. G.; Jørgensen, K. A. Angew. Chem. Int. Ed. 2007, 46, 9202.

(36) Murphy, J. J.; Quintard, A.; McArdle, P.; Alexakis, A.; Stephens, J. C. Angew. Chem. Int. Ed. 2011, 50, 5095.

(37) For seminal reports, see: Brandau, S.; Landa, A.; Franzén, J.; Marigo, M.; Jørgensen, K. A. Angew. Chem. Int. Ed. 2006, 45, 4305. For an account, see: Jensen, K. L.; Dickmeiss, G.; Jiang, H.; Albrecht, Ł.; Jørgensen, K. A. Acc. Chem. Res. 2012, 45, 248.

(38) For seminal reports on the use of diphenylprolinol silyl ethers as organocatalysts, see: (a) Mauro, M.; Wabnitz, T. C.; Fielenbach, D.; Jørgensen, K. A. Angew. Chem. Int. Ed. 2005, 44, 794. (b) Hayashi, Y.; Gotoh, H.; Hayashi, T.; Shoji, M. Angew. Chem. Int. Ed. 2005, 44, 4212.

(39) Cabrera, S.; Aleman, J.; Bolze, P.; Bertelsen, S.; Jørgensen, K. A. Angew. Chem. Int. Ed. 2008, 47, 121.

(40) McGarraugh, P. G.; Brenner, S. E. Org. Lett. 2009, 11, 5654.

(41) McGarraugh, P. G.; Jones, J. H.; Brenner-Moyer. S. E. J. Org. Chem. 2011, 76, 6309.

(42) Hong, B.-C.; Sadani, A. A.; Roshan, R. Y.; Dange, N. S.; Leeb, G.-H. Synthesis 2011, 1887.

(43) Hong, B.-C.; Nimje, R. Y.; Lin, C.-W.; Liao, J.-H. Org. Lett. 2011, 13, 1278.

(44) Hong, B.-C.; Liao, W.-K.; Dange, N. S.; Liao, J.-H. Org. Lett. 2013, 15, 468.

(45) Rajkumar, S.; Shankland, K.; Goodman, J. M.; Cobb, A. J. A. Org. Lett. 2013, 15, 1386.

(46) Xie, J.-W.; Chen, W.; Li, R.; Zeng, M.; Du, W.; Yue, L.; Chen, Y.-C.; Wu, Y.; Zhu, J.; Deng, J.-G. Angew. Chem. Int. Ed. 2007, 46, 389.

(47) For a review on this family of catalysts, see: Melchiorre, P.; Marigo, M.; Carlone, A.; Bartoli, G. Angew. Chem. Int. Ed. 2008, 47, 6138.

(48) Wu, L.-Y.; Bencivenni, G.; Mancinelli, M.; Mazzanti, A.; Bartoli, G.; Melchiorre, P. Angew. Chem. Int. Ed. 2009, 48, 7196.

(49) Bencivenni, G.; Wu, L.-Y.; Mazzanti, A.; Giannichi, B.; Pesciaioli, F.; Song, M.-P.; Bartoli, G.; Melchiorre, P. Angew. Chem. Int. Ed. 2009, 48, 7200.

(50) Cassani, C.; Tian, X.; Escudero-Adán, E. C.; Melchiorre, P. Chem. Commun. 2011, 47, 233.

(51) Zhang, J.-X.; Li, N.-K.; Liu, Z.-M.; Huang, X.-F.; Geng, Z.-C.; Wang, X.-W. Adv. Synth. Catal. 2013, 355, 797.

(52) Wei, Q.; Gong, L.-Z. Org. Lett. 2010, 12, 1008.

(53) (a) Li, X.-M.; Wang, B.; Zhang, J.-M.; Yan, M. Org. Lett. 2011, 13, 374. (b) De Fusco, C.; Lattanzi, A. Eur. J. Org. Chem. 2011, 3728.
(54) Wu, B.; Liu, G.-G.; Li, M.-Q.; Zhang, Y.; Zhang, S.-Y.; Qiu, J.-R.; Xu, X.-P.; Ji, S.-J.; Wang, X.-W. Chem. Commun. 2011, 47, 3992.

(55) Wang, L.-L.; Peng, L.; Bai, J.-F., Jia, L.-N., Luo, X.-Y., Huang, Q.-C., Xu, X.-Y.; Wang, L.-X. Chem. Commun. 2011, 47, 5593.

(56) (a) Wu, B.; Chen, J.; Li, M.-Q.; Zhang, J.-X.; Xu, X.-P.; Ji, S.-J.; Wang, X.-W. Eur. J. Org. Chem. 2012, 1318. (b) Li, X.; Yang, C.; Jin, J.-L.; Xue, X.-S.; Cheng, J.-P. Chem. Asian J. 2013, DOI: 10.1002/asia.201201244.

(57) For selected reviews, see: (a) Enders, D.; Niemeier, O.; Henseler, A. Chem. Rev. 2007, 107, 5606. (b) Moore, J. L.; Rovis, T. Top. Curr. Chem. 2010, 291, 77. (c) Bugaut, X.; Glorius, F. Chem. Soc. Rev. 2012, 41, 3511.

(58) Nair, V.; Menon, R. S.; Biju, A. T.; Sinu, C. R.; Paul, R. R.; Jose, A.; Sreekumar, V. Chem. Soc. Rev. 2011, 40, 5336.

(59) Fang, X.; Jiang, K.; Xing, C.; Hao, L.; Chi, Y. R. Angew. Chem. Int. Ed. 2011, 50, 1910.

(60) (a) Hoashi, Y.; Yabuta, T.; Takemoto, Y. Tetrahedron Lett. 2004, 45, 9185. (b) Hoashi, Y.; Yabuta, T.; Yuan, P.; Miyabe, H.; Takemoto, Y. Tetrahedron 2006, 62, 365.

(61) Thayumanavan, R.; Dhevalapally, B.; Sakthivel, K.; Tanaka, F.; Barbas III, C. F. Tetrahedron Lett. 2002, 43, 3817.

(62) Yu, D.-F.; Wang, Y.; Xu, P.-F. Adv. Synth. Catal. 2011, $353,2960$.

(63) Rajkumar, S.; Shankland, K.; Brown, G. D.; Cobb. A. J. A. Chem. Sci. 2012, 3, 584.

(64) Wang, X.-F.; Chen, J.-R.; Cao, Y.-J.; Cheng, H.-G.; Xiao, W.-J. Org. Lett. 2010, 12, 1140.

(65) Cao, C.-L.; Zhou, Y.-Y.; Zhou, J.; Sun, X.-L.; Tang, Y.; Li, Y.-X.; Li, G.-Y.; Sun, J. Chem. Eur. J. 2009, 15, 11384.

(66) Hong, B.-C.; Lan, D.-J.; Dange, N. S.; Lee, G.-H.; Liao, J.-H. Eur. J. Org. Chem. 2013, DOI : 10.1002/ejoc.201201496

(67) Wong, C. T. Tetrahedron 2012, 68, 481.

(68) Chintala, P.; Ghost, S. K.; Long, E.; Headley, A. D.; Ni, B. Adv. Synth. Catal. 2011, 353, 2905.

(69) Hong, B.-C.; Kotame, P.; Liao, J.-H. Org. Biomol. Chem. 2011, 9, 382.

(70) Tan, B.; Chua, P. J.; Li, Y.; Zhong, G. Org. Lett. 2008, 10, 2437.

(71) Varga, S.; Jakab, G.; Drahos, L.; Holczbauer, T.; Czugler, M.; Soós, T. Org. Lett. 2011, 13, 5416.

(72) Cagide-Fajín, F.; Nieto-García, O.; Lago-Santomé, H.; Alonso, R. J. Org. Chem. 2012, 77, 11377.

(73) Zhou, J.; List, B. J. Am. Chem. Soc. 2007, 129, 7498.

(74) Dai, Q.; Arman, H.; Zhao, J. C.-G. Chem. Eur. J. 2013, 19, 1666.

(75) Quintavalla, A.; Lombardo, M.; Sanap, S. P. Trombinia, C. Adv. Synth. Catal. 2013, DOI: 10.1002/adsc. 201201135 
(76) (a) Beeson, T. D.; Mastracchio, A.; Hong, J.; Ashton, K.; MacMillan, D. W. C. Science 2007, 316, 582. (b) Jang, H.; Hong, J.; MacMillan, D. W. C. J. Am. Chem. Soc. 2007, 129, 7004.

(77) Jui, N. T.; Lee, E. C. Y.; MacMillan, D. W. C. J. Am. Chem. Soc. 2010, 132, 10015

(78) (a) Multicomponent Reactions (Eds.: Zhu, J.; Bienaymé, H.), Wiley-VCH, Weinheim, 2005. For some recent reviews, see: (b) Isambert, N.; Sanchez Duque, M. M.; Plaquevent, J-C.; Génisson, Y.; Rodriguez, J.; Constantieux, T. Chem. Soc. Rev. 2011, 40, 1347. (c) Dömling, A.; Wang, W.; Wang, K. Chem. Rev. 2012, 112, 3083. (d) Shiri, M. Chem. Rev. 2012, 112, 3508. (e) Marson, C. M. Chem. Soc. Rev. 2012, 41, 7712. (f) van Berkel, S. S.; Bögels, B. G. M.: Wijdeven, M. A.; Westermann, B.; Rutjes, F. P. J. T. Eur. J. Org. Chem. 2012, 3543. (g) de Graaff, C.; Ruijter, E.; Orru, R. V. A. Chem. Soc. Rev. 2012, 41, 3969.

(79) For leading references, see: (a) Enders, D.; Grondal, C.; Hüttl, M. R. M. Angew. Chem., Int. Ed. 2007, 46, 1570. (b) Yu, X.; Wang, W. Org. Biomol. Chem. 2008, 6, 2037. (c) Grondal, C.; Jeanty M.; Enders, D. Nature Chem. 2010, 2, 167. (d) Grossmann, A.; Enders, D. Angew. Chem., Int. Ed. 2012, 51, 314.

(80) Enders, D.; Hüttl, M. R. M.; Grondal, C.; Raabe, G. Nature 2006, 441, 861.

(81) Jai, Y.; Mao, Z.; Wang, R. Tetrahedron: Asym. 2011, 22, 2018.

(82) For a discussion on the terminology, see: Coquerel, Y.; Boddaert, T.; Presset, M.; Mailhol, D.; Rodriguez, J. in Ideas in Chemistry and Molecular Sciences: Advances in Synthetic Chemistry, (Ed.: B. Pignataro), Wiley-VCH: Weinheim, Germany, 2010, Chap. 9, pp. 187.

(83) Baslé, O.; Raimondi, W.; Sanchez Duque, M. M.; Bonne, D.; Constantieux, T.; Rodriguez, J. Org. Lett. 2010, 12, 5246.

(84) Mao, Z.; Jia, Y.; Xu, Z.; Wang, R. Adv. Synth. Catal. 2012, 354, 1401.

(85) Rueping, M.; Haack, K. L.; Ieawsuwan, W.; Sundén, H.; Blanco, M.; Schoepke, F. R. Chem. Commun. 2011, 47, 3828.

(86) Zeng, X.; Ni, Q.; Raabe, G.; Enders, D. Angew. Chem. Int. Ed. 2013, DOI: 10.1002/anie.201209581.

(87) Carlone, A.; Cabrera, S.; Marigo, M.; Jørgensen, K. A. Angew. Chem. Int. Ed. 2007, 46, 1101.
(88) Enders, D.; Jeanty, M.; Bats, J. W. Synlett 2009, 3175.

(89) Companyó, X.; Zea, A.; Alba, A-N. R.; Mazzanti, A.; Moyano, A.; Rios, R. Chem. Commun. 2010, 46, 6953.

(90) Alba, A-N. R.; Zea, A.; Valero, G.; Calbet, T.; FontBardía, M.; Mazzanti, A.; Moyano, A.; Rios, R. Eur. J. Org. Chem. 2011, 1318.

(91) Enders, D.; Greb, A.; Deckers, K.; Selig, P.; Merkens, C. Chem. Eur. J. 2012, 18, 10226.

(92) Bertelsen, S.; Johansen, R. L.; Jørgensen, K. A. Chem. Commun. 2008, 3016

(93) Enders, D.; Urbanietz, G.; Cassens-Sasse, E.; Keeb, S.; Raabe, G. Adv. Synth. Catal. 2012, 354, 1481.

(94) García Ruano, J. L.; Marcos, V.; Suanzes, J. A.; Marzo, L.; Alemán, J. Chem. Eur. J. 2009, 15, 6576.

(95) Hong, B.-C.; Dange, N. S.; Ding, C.-F.; Liao, J.-H. Org. Lett. 2012, 14, 448.

(96) Enders, D.; Hüttl, M. R. M.; Runsik, Y.; Raabe, G.; Wendt, B. Angew. Chem. Int. Ed. 2007, 46, 467. Enders, D.; Hüttl, M. R. M.; Raabe, G.; Bats, J. W. Adv. Synth. Catal. 2008, 350, 267.

(97) Enders, D.; Schmid, B.; Erdmann, N. Synthesis 2010, 2271.

(98) Erdmann, N.; Philipps, A. R.; Atodiresei, I.; Enders, D. Adv. Synth. Cat. 2013, DOI/10.1002/adsc.201201099.

(99) Wang, Y.; Han, R.-G.; Zhao, Y.-L.; Yang, S.; Xu, P.-F.; Dixon, D. J. Angew. Chem., Int. Ed. 2009, 48, 9834.

(100) Zhou, B.; Yang, Y.; Shi, J.; Luo, Z.; Li, Y. J. Org. Chem. 2013, DOI/10.1021:jo302655u.

(101) Tokoroyama, T. Eur. J. Org. Chem. 2010, 2009.

(102) Jensen, K. L.; Dickmeiss, G.; Jiang, H.; Albrecht, Ł.; Jørgensen, K. A. Acc. Chem. Res. 2012, 45, 248.

(103) (a) Jiang, K.; Jia, Z.-J.; Yin, X.; Chen, S.; Wu, L.; Chen, Y.-C. Chem. Eur. J. 2010, 16, 2852. (b) Jiang, K.; Jia, Z.-J.; Yin, X.; Wu, L.; Chen, Y.-C. Org. Lett. 2010, 12, 2766.

(104) Zea, A.; Alba, A.-N. R.; Mazzanti, A.; Moyano, A.; Rios, R. Org. Biomol. Chem. 2011, 9, 6519.

(105) (a) Bhanja, Jena, S.; Nayak, S.; Mohapatra, S. Beilstein J. Org. Chem. 2012, 8, 1668. (b) Nising, C. F.; Bräse, S. Chem. Soc. Rev. 2012, 41, 988.

(106) (a) Kotame, P.; Hong, B.-C.; Liao, J.-H., Tetrahedron Lett. 2009, 50, 704. (b) Hong, B.-C.; Kotame, P.; Tsai, C.-W.; Liao, J.-H., Org. Lett. 2010, 12, 776.

(107) Zhang, F.-L.; Xu, A.-W.; Gong, Y.-F.; Wei, M.-H.; Yang, X.-L. Chem. Eur. J. 2009, 15, 6815. 


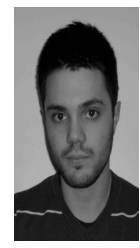

Sébastien Goudedranche was born in Mulhouse (Alsace, France) in december 1988. In 2011, He obtained his M.Sc. (synthetic organic chemistry) degree from Université de Haute-Alsace (France). He is now pursuing his PhD under the supervision of Pr. Thierry Constantieux and Dr. Damien Bonne in the STeRéO group, at Aix-Marseille Université (France). His research focuses on the development of new organocatalyzed methodologies.

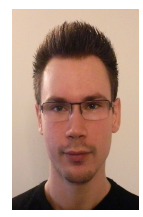

Dr. Wilfried Raimondi was born in Orsay (France) in June 1986. In 2006, he joined the Ecole Nationale Supérieure de Chimie de Clermont Ferrand (ENSCCF) where he was awarded both his MSc and BSc in chemistry. He carried out his $\mathrm{PhD}$ under the supervision of Pr. Jean Rodriguez and Dr. Damien Bonne at Aix-Marseille Université, where he worked on the development of new organocatalyzed methodologies.

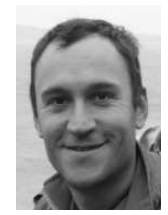

Damien Bonne was born in Epinal (France) in 1979. After studying chemistry at the Ecole Supérieure de Chimie de Lyon (CPE Lyon, France), he completed his $\mathrm{PhD}$ in 2006 under the supervision of Prof. Jieping Zhu working on isocyanide-based multicomponent reactions. He then moved to the University of Bristol (UK) to join the group of Prof. Varinder Aggarwal as a post-doctoral associate. Since 2007 he has been working as an assistant professor with Prof. Jean Rodriguez at Aix-Marseille Université (France). His research interests include the development of new asymmetric organocatalyzed methodologies and their applications in stereoselective synthesis.

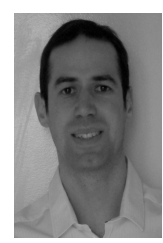

Xavier Bugaut was born in Saint-Rémy (France) in 1982. After graduating at the Ecole Nationale Supérieure de Chimie de Montpellier (France), he carried out his doctoral work on the synthesis of landomycinone under the supervision of Dr. Emmanuel Roulland, at the Institut de Chimie des Substances Naturelles, Gif-sur-Yvette (France). He then joined the group of Prof. Frank Glorius at the Westfälische-Wilhems Universität Münster (Germany) as a postdoctoral fellow, focusing on the development of new NHC-catalyzed transformations. In October 2011 he was appointed Maître de Conférences (equivalent to assistant professor) at Aix-Marseille Université (France) in the group of Prof. Jean Rodriguez and Prof. Thierry Constantieux. His current research interests include enantioselective organocatalysis, with a focus on its application to multicomponent reactions and the development of new modes of actions for organocatalysts.

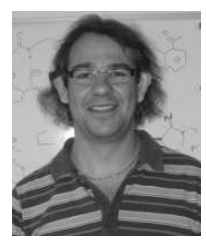


Thierry Constantieux was born in Pau, France, on 6 may 1968. After studying chemistry at the University Bordeaux I, he completed his PhD under the supervision of Dr. J.-P. Picard and Dr. J. Dunoguez in 1994. He completed his Habilitation in 2004, at Aix-Marseille Université (France), where he is currently Professor of Organic Chemistry. His main research interest is focused on the development of new eco-compatible synthetic methodologies, especially enantioselective organocatalyzed cascades and domino multicomponent reactions from 1,3-dicarbonyl compounds, and their applications in heterocyclic chemistry.

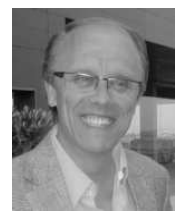

Jean Rodriguez was born in Cieza (Spain) in 1958 and in 1959 his family emigrated to France. After studying chemistry at Aix-Marseille Université (France), he completed his Ph.D. as a CNRS researcher with Prof. Bernard Waegell and Prof. Pierre Brun in 1987. He completed his Habilitation in 1992, also at Marseille, where he his currently Professor and Director of the UMR-CNRS-7313-iSm2. His research interests is focused on the development of new Multiple Bond-Forming Transformations (MBFTs) including domino and multicomponent reactions, and their application in organocatalytic stereoselective synthesis. In 1998 he was awarded the ACROS prize in Organic Chemistry, and in 2009 he was awarded the prize of the Division of Organic Chemistry from the French Chemical Society.

Please place the graphical abstract and short title of the article here. The short title will be used as a running header.

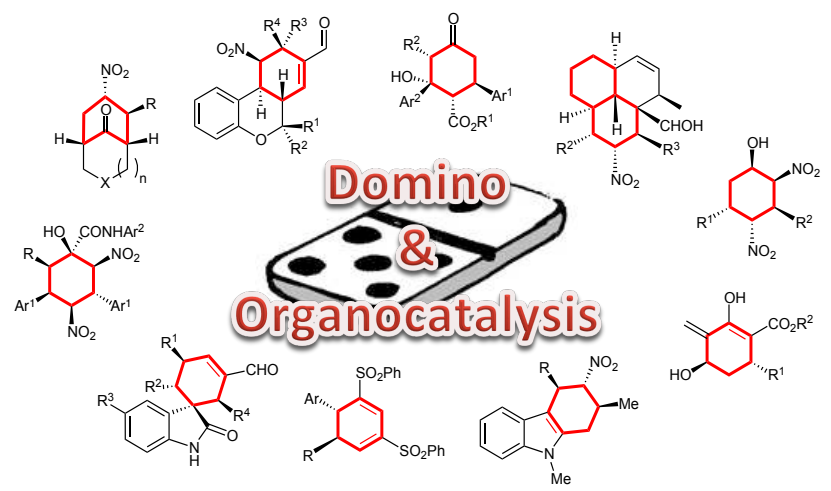

Enantioselective organocatalyzed domino synthesis of six-membered carbocycles. Polysubstituted chiral cyclohexanes and cyclohexenes are important building blocks in organic synthesis. From historical and pioneer reports to the most recent accounts, this review focuses on domino enantioselective organocatalytic methodologies that have allowed the control of the relative and absolute configurations in the construction of these versatile molecular architectures.

\section{Manuscript submission checklist}

- Statement of significance of work.

- Full mailing address, telephone, and fax numbers, and email address of the corresponding author.

- Graphical abstract.

- 5 key words.

- Original Word file.

- Original graphics files.

- Biographical sketches of the authors. 
- Photographs of the authors.

Proceed to submit your article via our online submission system at $\mathrm{http}: / / \mathrm{mc}$.manuscriptcentral.com/synthesis. When prompted to "Add an Editor", please select the Editor who invited you to submit this Review or Short Review. 